\title{
A rare human centenarian variant of SIRT6 enhances genome stability and interaction with Lamin A
}

Matthew Simon $^{1,} \uparrow$, Jiping Yang ${ }^{2,} \uparrow$, Jonathan Gigas ${ }^{1}$, Eric J. Earley ${ }^{3}$, Tory M. Schaff ${ }^{4}$, Lei Zhang $^{4}$, Maria Zagorulya ${ }^{1}$, Greg Tombline ${ }^{1}$, Michael Gilbert ${ }^{5}$, Samantha L. Yuen ${ }^{4}$, Alexis Pope $^{2}$, Michael Van Meter ${ }^{1}$, Stephan Emmrich ${ }^{1}$, Jeehae Han ${ }^{6}$, Seungjin Ryu ${ }^{6}$, Archana Tare $^{6}$, Yizhou Zhu', Adam Hudgins ${ }^{6}$, Gil Atzmon ${ }^{6,7}$, Nir Barzilai ${ }^{6}$, Aaron Wolfe ${ }^{8}$, Kelsey Moody ${ }^{8}$, Benjamin A. Garcia ${ }^{5}$, David D. Thomas ${ }^{4}$, Paul D. Robbins ${ }^{4}$, Jan Vijg ${ }^{6}$, Andrei Seluanov ${ }^{2, *}$, Yousin Suh ${ }^{3, *}$, Vera Gorbunova ${ }^{2, *}$

${ }^{1}$ Department of Biology, University of Rochester; Rochester NY 14627, USA

${ }^{2}$ Department of Obstetrics and Gynecology, Columbia University; New York, NY 10032, USA

${ }^{3}$ Biostatistics and Epidemiology, RTI International, Durham, NC, USA

${ }^{4}$ Department of Biochemistry, Molecular Biology and Biophysics and Institute on the Biology of Aging and Metabolism, University of Minnesota; Minneapolis, MN 55455

${ }^{5}$ Department of Biochemistry and Biophysics, Perelman School of Medicine, University of Pennsylvania; Philadelphia, Pennsylvania 19104, USA

${ }^{6}$ Department of Genetics, Albert Einstein College of Medicine; Bronx, NY, USA.

${ }^{7}$ Department of Biology, Faculty of Natural Sciences, University of Haifa; Haifa, Israel 31905

${ }^{8}$ Ichor Therapeutics; 2521 US-11, Lafayette, NY 13084, USA

$\dagger$ Equal contribution

*Correspondence should be addressed to andrei.seluanov@ rochester.edu or ys3214@cumc.columbia.edu or vera.gorbunova@ rochester.edu

KEYWORDS: Centenarians/Lamin/Longevity/SIRT6 


\section{SUMMARY}

Sirtuin 6 (SIRT6) is a deacylase and mono-ADP ribosyl transferase (mADPr) enzyme involved in multiple cellular pathways implicated in the regulation of aging and metabolism. Targeted sequencing identified a SIRT6 allele containing two linked substitutions (N308K/A313S) as enriched in Ashkenazi Jewish (AJ) centenarians as compared to AJ control individuals. Characterization of this SIRT6 (centSIRT6) allele demonstrated it to be a stronger suppressor of LINE1 retrotransposons, confer enhanced stimulation of DNA double strand break repair, and more robust cancer cell killing compared to the wild type. Surprisingly, centSIRT6 displayed weaker deacetylase activity, but stronger mADPr activity, over a range of $\mathrm{NAD}^{+}$concentrations and substrates. Additionally, centSIRT6 displayed a stronger interaction with Lamin A/C (LMNA), which correlated with enhanced ribosylation of LMNA. Our results suggest that enhanced SIRT6 function contributes to human longevity by improving genome maintenance via increased mADPr activity and enhanced interaction with LMNA.

\section{INTRODUCTION}

SIRT6 is a protein deacylase and mono-ADP-ribosylase (mADPr) enzyme that has diverse cellular functions, many of which are related to aging and longevity. SIRT6 knockout mice show premature aging and genomic instability (Mostoslavsky, Chua et al., 2006) while mice overexpressing SIRT6 display an extended lifespan (Kanfi, Naiman et al., 2012, Roichman, Elhanati et al., 2021). Across mammalian species, SIRT6 is conserved and its activity has a strong positive correlation with maximum lifespan (Tian, Firsanov et al., 2019). At the molecular level, SIRT6 is involved in DNA repair, telomere maintenance, silencing of the repetitive elements including LINE1 retrotransposons, regulation of glucose homeostasis, inflammation and pluripotency (Etchegaray \& Mostoslavsky, 2015, Kawahara, Michishita et al., 2009, Mao, Hine et al., 2011, Michishita, McCord et al., 2008, Mostoslavsky et al., 2006, Van Meter, Kashyap et al., 2014, Van Meter, Simon et al., 2016). In addition, SIRT6 is a noted tumor suppressor (Min, Ji et al., 2012, Sebastian, Zwaans et al., 2012, Van Meter, Mao et al., 2011). 
Cells lacking SIRT6 are more susceptible to malignant transformation, while SIRT6 overexpression induces apoptosis in cancer cells, but not in normal cells (Van Meter et al., 2011).

SIRT6 is localized in the nucleus where it interacts with nuclear scaffold protein Lamin A/C (LMNA) (Ghosh, Liu et al., 2015), which is also implicated in human longevity. Mutations in LMNA cause a multitude of human genetic syndromes, many of them associated with premature aging, including Hutchinson Gilford progeria syndrome (HGPS) (De SandreGiovannoli, Bernard et al., 2003, Eriksson, Brown et al., 2003). Interaction with LMNA activates SIRT6 enzymatic activities (Ghosh et al., 2015). Early onset premature aging observed in SIRT6 deficient mice resembles HGPS, which led to the suggestion that abnormal SIRT6 localization and function in HGPS drives the disease pathogenesis (Ghosh et al., 2015). A coding change in SIRT6, SIRT6 D63H, leads to the loss of SIRT6 enzymatic activity and embryonic lethality (Ferrer, Alders et al., 2018).

The strong correlation between SIRT6 activity and longevity across species (Tian et al., 2019) and in genetically modified mice (Kanfi et al., 2012, Roichman et al., 2021) raises the question of whether higher SIRT6 activity may be associated with longer lifespan in humans. Non-coding genetic polymorphisms in the SIRT6 gene region were associated with human longevity in candidate SNP analyses (Hirvonen, Laivuori et al., 2017, Li, Qin et al., 2016, TenNapel, Lynch et al., 2014). To date no beneficial mutations in SIRT6 associated with longevity have been functionally characterized.

In this study, we identified two novel variants of SIRT6 enriched in a population of human centenarians. One of these variants, centSIRT6 possesses altered biological activities compared to the common allele. centSIRT6 allele demonstrates enhanced mono-ADP ribosylase activity, but a reduced deacetylase activity in vitro. This tradeoff in activity produces an allele that confers enhancement in DNA repair and enhanced suppression of transposable elements, as well as a resistance to oxidative stress. Additionally, the centenarian allele is more efficient at killing cancer cells. Functionally, we found that the centenarian allele shows an enhanced interaction with LMNA, which correlates with an increased ribosylation state of LMNA. Together, we identified a novel centenarian allele of SIRT6 that results in enhanced genome maintenance by shifting the balance between the deacetylation and mADPr activities of SIRT6. 


\section{RESULTS}

To examine whether variants of SIRT6 are associated with human longevity we performed targeted sequencing of SIRT6 locus in a population of 496 Ashkenazi Jewish (AJ) centenarians and $572 \mathrm{AJ}$ controls (individuals without a family history of exceptional longevity). Table 1 shows all the SNPs identified. We observed association of rs350845 with living beyond 100 years $(\mathrm{P}=0.049$, Table 1). This SNP lies within a SIRT6 intron and is an eQTL for SIRT6 upregulation across 18 tissue types (Fig EV1). Interestingly, this SNP is in high linkage disequilibrium LD (r2 > 0.98) with two other eQTLs, rs350843 and rs350846, which also upregulate SIRT6.

In addition, two rare missense variants in perfect linkage were observed, rs183444295 (A313S) and rs201141490 (N308K), aka centSIRT6, which had nearly double the allele frequency among centenarians (1.0\%) compared to both study controls $(0.55 \%)$ as well as a separate AJ cohort within GnomAD which did not contain centenarians (0.60\%), although this difference was not statistically significant $(\mathrm{P}=0.7, \mathrm{P}=0.5$, respectively) due to lack of power.

Analysis of the entire GnomAD database (141,456 individuals of diverse ethnic backgrounds), uncovered an apparent enrichment of centSIRT6 allele pair among the 75+ age group compared to other age groups. Compared to other alleles at similar MAF $(0.1-1 \%)$, the centSIRT6 allele was in the top $5^{\text {th }}$ percentile of $75+$ enriched SNPs and in the $9^{\text {th }}$ percentile of all missense mutations (Fig 1A, B). We sought to characterize this missense mutation to discover its molecular impacts on SIRT6 function in the context of extreme longevity (Fig 1C).

\section{centSIRT6 demonstrates reduced deacetylase activity in vitro}

SILAC analysis of HEK293 cells expressing different SIRT6 alleles showed no difference in the protein turnover rates between the WT and centSIRT6 (Fig EV2A). To assess the biochemical properties of the different SIRT6 alleles, we purified recombinant versions of each allele (Fig EV2B). Consistent with similar half-lives of wild type and centSIRT6 in vivo, we found no notable differences in the thermal stability of the SIRT6 alleles in vitro, suggesting that centSIRT6 does not grossly alter the folding or the ambient stability (Fig EV2C). As centSIRT6 mutations change the polarity and charge of the residues, we used SIRT6 FRET biosensors fused to the middle and the C-terminus of SIRT6 to assess for more subtle changes to protein structure that centSIRT6 mutations might cause (Fig EV2D-G). The centSIRT6 
decreased FRET by $\Delta \mathrm{E}=6.4 \pm 0.1 \%$ relative to the wild type SIRT6, corresponding to an increase in the donor-acceptor distance $\mathrm{R}$ by $3.0 \pm 0.4 \AA$. This increase indicates centSIRT6 mutations shift the SIRT6 structure toward a more open conformation.

We then tested SIRT6 deacylase activity (Jiang, Khan et al., 2013) on a myristoylated peptide to determine $\mathrm{K}_{\mathrm{m}}$ for $\mathrm{NAD}^{+}$and peptide for wild type and centSIRT6. While the centenarian allele displayed a slight reduction in activity $\left(\mathrm{V}_{\max }\right)$ compared to the wild type $(p=$ 0.02) (Fig 1C), $\mathrm{K}_{\mathrm{m}}$ was not significantly different between wild type and centSIRT6 for both substrates. Quenching of SIRT6 intrinsic Trp fluorescence by NAD ${ }^{+}$binding also showed that centSIRT6 has similar affinity for $\mathrm{NAD}^{+}$to the wild type allele (Fig EV2H). Overall, these data indicate that centSIRT6 confers a slight reduction in deacylase catalytic efficiency (as defined by $\left.\mathrm{V}_{\max } / \mathrm{K}_{\mathrm{m}}\right)($ Fig 1C).

The centSIRT6 displayed significantly lower deacetylase activity on recombinant nucleosomes with saturated H3K9ac and H3K18ac modifications (Fig 1E, F). Additionally, centSIRT6 allele displayed significantly slower histone deacetylase kinetics (Fig 2A, B). Similar to the synthetic histones, the centSIRT6 allele deacetylated both H3K9ac and H3K18ac residues on nucleosomes purified from HeLa cells, at a significantly reduced rate compared to the wild type SIRT6 (Fig EV3A). Taken together, the combined data from deacylase and histone deacetylase experiments indicate that the centSIRT6 variant has reduced deacylase/deacetylase activity.

To test the effect of the centSIRT6 allele on histone deacetylation activity in vivo, we generated telomerase-immortalized human HCA2 fibroblast cell lines in a SIRT6 KO background containing a cumate switch promoter driving expression of SIRT6 WT, N308K, A313S, and the centSIRT6 alleles (cumate SIRT6 fibroblasts). Each cell line was induced with cumate to drive equal levels of SIRT6 expression (Fig EV3B, EV3C). We quantified histone post-translational modifications from purified histones (Fig EV3D) from these cells by mass spectrometry using peptide standards as described previously (Sidoli, Bhanu et al., 2016). Cells expressing the centSIRT6, N308K, and A313S SIRT6 alleles showed similar global histone post translational modification (PTM) levels at all sites known to be SIRT6 substrates including H3K9ac, H3K18ac, and H3K56ac (Fig 2C; Data S1). Similarly, global levels of H3K9ac and H3K18ac measured by Western blot did not show significant changes, even when challenged with paraquat-induced oxidative damage (Fig 2D). These results suggest that while centSIRT6 
enzyme has reduced catalytic efficiency of deacetylation, its activity is sufficient to maintain normal steady state levels of PTMs in vivo.

\section{mADPr activity is enhanced in centSIRT6}

In addition to its deacetylase activity, SIRT6 has mono-ADP ribosylation (mADPr) activity, able to mono-ADP ribosylate itself and other proteins. mADPr activity is critical to SIRT6 role in DNA damage response and LINE1 repression (Kaidi, Weinert et al., 2010, Mao et al., 2011, Van Meter et al., 2014). To assess the mADPr activity, two known SIRT6 substrates were used: PARP1 and SIRT6, itself. The centSIRT6 demonstrated an enhanced autoribosylation rate with biotin-labeled $\mathrm{NAD}^{+}$than the wild type SIRT6 (Fig 3A). The single SNPs did not display a notable difference in self-mADPr compared to the wild type, suggesting the increase observed in the centenarian allele results from a synthetic interaction that is not cumulative between the two SNPs (Fig 3A). Following this, we utilized an antibody (Bonfiglio, Leidecker et al., 2020) with specificity to mADPr residues to examine the self-ribosylation efficiency using a titration of $\mathrm{NAD}^{+}$. centSIRT6 displayed an apparent $\mathrm{NAD}^{+}$affinity $\left(\mathrm{K}_{\mathrm{app}} \mathrm{NAD}\right)$ of $142 \pm 29 \mu \mathrm{M}$ and maximal relative auto-ribosylation $m A D \operatorname{Pr}_{\max }$ of 5.27 whereas wild type SIRT6 displayed $\mathrm{K}_{\mathrm{app} \mathrm{NAD}}=106 \pm 45 \mu \mathrm{M}$ and $\mathrm{mADPr}_{\max }$ of 2.48. Thus, the overall efficiency as defined by $\mathrm{mADPr}_{\max } / \mathrm{K}_{\text {app NAD }}$ was 0.037 for centSIRT6 compared to 0.023 for wild type SIRT6, which also equates to a nearly two-fold difference (Fig 3B). In trans, mADPr activity was assessed by incubation with human PARP1, which was previously shown to be ribosylated by SIRT6 (Mao et al., 2011). Similar to self-ribosylation, the centSIRT6 displayed higher PARP1 ribosylation activity (Fig 3C). While both single mutants had elevated activity, the A313S allele was more similar to the centSIRT6 than N308K (Fig 3C). Collectively, these data show that centSIRT6 displays enhanced mADPr activity.

\section{centSIRT6 is more efficient at suppressing LINE1s and cancer cell killing}

SIRT6 suppresses the expression of LINE1 retrotransposons via its mADPr activity (Van Meter et al., 2014). The loss of silencing of these elements contributes to age-related sterile inflammation and drives progeroid phenotypes in SIRT6 KO mice (Simon, Van Meter et al., 2019). To assess the capacity of the centSIRT6 allele to silence LINE1 transposons, we used the cumate-inducible fibroblasts expressing alleles of SIRT6. qRT-PCR analysis of both 5'- and 3'- 
biased regions of an evolutionarily active family of LINE1s both showed that the centSIRT6 allele enhances LINE1 suppression compared to the wild type SIRT6, as did the N308K allele (Fig 4A). The A313S allele showed a slight trend towards stronger suppression, but did not show a significant improvement over the wild type SIRT6 when assessed for the 3' bias. These results show that centSIRT6 is more efficient at silencing LINE1 elements, which are functionally implicated in longevity.

SIRT6 as a major regulator of DNA double strand break (DSB) (Mao et al., 2011). To quantify the differences between the SIRT6 alleles at promoting DSB repair, we employed in vivo GFP-based assays that measure nonhomologous end joining (NHEJ) and homologous recombination (HR) repair of a chromosomal DSB induced by I-SceI enzyme (Seluanov, Mao et al., 2010). Different alleles of SIRT6 were transiently expressed in the NHEJ and HR reporter telomerase-immortalized human foreskin fibroblast cell lines (Mao, Bozzella et al., 2008). We found that equivalent amounts of the centSIRT6 stimulated NHEJ 2.5-fold and HR 2-fold greater than the wild type SIRT6 (Fig 4B, C; Fig EV4A). Similarly, we observed in the cumate SIRT6 fibroblasts expressing centSIRT6 that basal levels of $\gamma \mathrm{H} 2 \mathrm{AX}$ foci were reduced by $50 \%$ relative to those observed in either single alleles or the wild type SIRT6 (Fig 4D; Fig EV4B). Taken together, these data indicate that the centSIRT6 allele elicits enhanced DNA DSB repair activity. We next compared whether different SIRT6 alleles have different effects upon stress. Using the cumate SIRT6 fibroblasts, we exposed the cells to $\gamma$-radiation and assessed the resolution of DSBs over time via $\gamma \mathrm{H} 2 \mathrm{AX}$ immunostaining. We observed that while both wild type and centSIRT6-expressing cell lines had similar levels of $\gamma \mathrm{H} 2 \mathrm{AX}$ foci immediately after exposure, the centSIRT6-expressing cells showed an improved recovery rate (Fig 4E, Fig EV4C). Furthermore, we found that the centSIRT6-expressing cells were more resistant to oxidative stress-induced apoptosis (Fig 4F, G, Fig EV4D). In contrast, in the absence of cumate induction, all cell lines showed no significant differences in survival after oxidative stress (Fig 4F). Taken together, these results indicate that the centSIRT6 improves DSB repair and resistance to DNA damage.

To further confirm that centSIRT6 enhances genome maintenance we generated knock-in human embryonic stem cells carrying centSIRT6 allele. The two centenarian mutations were introduced using CRISPR CAS9, and confirmed by sequencing. We generated two independent knock-in clones and differentiated them into MSCs. The MSCs were then transfected with 
linearized NHEJ and HR GFP reporters (Mao et al., 2008). Cells harboring centSIRT6 allele showed higher efficiency of repair (Fig EV5A, EV5B). These cells were also showed increased survival and lower number of 53BP1 foci upon treatment with methyl methanesulfonate (MMS), a potent DNA-damaging agent (Fig EV54C, EV5D). Interestingly, the centSIRT6 knock-in cells showed higher protein and mRNA levels of SIRT6 (Fig EV5E, EV5F), suggesting that centenarian mutations increase mRNA stability, in addition to modulating SIRT6 enzymatic activities. As it was impossible to compare equal levels of SIRT6 in CRISPR knock-in cells, we relied on cumate cells for the majority of our in vivo assays.

SIRT6 overexpression induces apoptosis in cancer cells but not in normal cells (Van Meter et al., 2011). In order to assess the tumor cell killing capacity of the centSIRT6 allele, we transfected SIRT6 alleles into two common tumor cell lines, HT1080 and HeLa cells. Expression of the centSIRT6 resulted in $\sim 2$-fold fewer adherent surviving cells in both cancer cell lines compared to wild type SIRT6 (Fig 5A). Additionally, the centSIRT6 allele triggered at least 2fold higher levels of apoptosis than the wild type SIRT6 allele in these cancer cell lines (Fig 5B, C). These data indicate that, centSIRT6 confers a more robust anti-tumor activity than the wild type SIRT6.

\section{centSIRT6 displays higher affinity for LMNA}

Since the centSIRT6 mutations are located in the flexible C-terminus of SIRT6 and may influence protein-protein interactions, we compared the interactomes of the centSIRT6 and the wild type alleles. We used antibodies against SIRT6 to immuno-precipitate SIRT6-interacting proteins from cumate SIRT6 fibroblasts and analyzed them by mass spectrometry with tandemmass tags (TMT) to permit accurate quantitation. Several interacting proteins were enriched by the centSIRT6 allele (Fig 6A; Data S2). Most notable proteins showing stronger interaction with centSIRT6 than the wild type SIRT6 were LMNA and vimentin (VIME), which showed 38 and 40 peptides respectively. Both of these proteins are known to interact with SIRT6 (Ghosh et al., 2015, Gioutlakis, Klapa et al., 2017, Huttlin, Ting et al., 2015, Oughtred, Stark et al., 2019, Patil \& Nakamura, 2005), and LMNA was shown to stimulate SIRT6 activity (Ghosh et al., 2015). No loss or gain of interactions was apparent in the centSIRT6 set, indicating that the effect of the novel allele could be in enhancing existing SIRT6 interactions. 
LMNA is a nuclear scaffold protein playing a central role in nuclear organization and is also implicated in aging. To confirm the mass spec data on SIRT6 and LMNA interactions, we performed co-IP with SIRT6 antibodies followed by Western blot with LMNA antibodies using cumate SIRT6 fibroblasts. We found that centSIRT6, indeed, associates more strongly with LMNA than the wild type SIRT6 allele (Fig 6B, C) and the effect was reciprocal as assessed by co-IP with LMNA antibodies followed by Western blot with SIRT6 antibodies (Fig 6B, D). Taken together these results demonstrate that centSIRT6 interacts more strongly with LMNA than the wild type SIRT6. Given the enhanced mADPr activity of the centSIRT6 allele, we next assessed the ribosylation status of LMNA using the mADPr antibodies. SIRT6 IPs performed on the cumate SIRT6 fibroblasts, using the mADPr specific antibody (Bonfiglio et al., 2020), showed that centSIRT6 was more ribosylated in vivo (Fig 6B, E); as demonstrated in vitro with the purified SIRT6 proteins (Fig 3A). IP with mADPr specific antibody (Bonfiglio et al., 2020) and subsequent Western blot with an anti-LMNA antibody revealed increased ribosylation of LMNA in the presence of the centSIRT6 allele (Fig 6B, F). LMNA has been reported to be ADP ribosylated in vivo on several residues (Adolph, 1987, Adolph \& Song, 1985, Hendriks, Larsen et al., 2019).

We hypothesized that the centSIRT6 allele may influence the interaction of LMNA with other proteins. To test this, we immuno-precipitated LMNA from the cumate fibroblasts expressing either the wild type SIRT6 or centSIRT6 alleles and performed quantitative protein interaction analysis using TMT labeling followed by mass spectrometry. While many proteins showed similar interaction with LMNA, regardless of the SIRT6 allele present, a large group of proteins showed enhanced interaction with LMNA in the presence of centSIRT6 (Fig 6G; Data S3). LMNA-interaction partners enhanced by sentSIRT6 included ELAVL1, FUS, PCBP2, SAFB, SRSF1, SRSF3, TFIP11, THRAP3, BCLAF1, and U2AFBP all proteins that facilitate the coordination of the DNA damage response with RNA processing (Beli, Lukashchuk et al., 2012, Montecucco \& Biamonti, 2013, Naro, Bielli et al., 2015, Vohhodina, Barros et al., 2017). Many of the proteins identified in SIRT6 and LMNA IPs are ADP-ribosylated (Bilan, Leutert et al., 2017, Hendriks et al., 2019, Jungmichel, Rosenthal et al., 2013, Leslie Pedrioli, Leutert et al., 2018, Martello, Leutert et al., 2016, Vivelo, Wat et al., 2017) (shown as hexagons in Fig 6G), suggesting that ADP-ribosylation by SIRT6 may play a role in mediating these interactions. Taken together, our data show that centSIRT6 is more efficient at promoting DNA repair and 
bioRxiv preprint doi: https://doi.org/10.1101/2021.12.13.472381; this version posted December 13, 2021. The copyright holder for this preprint (which was not certified by peer review) is the author/funder, who has granted bioRxiv a license to display the preprint in perpetuity. It is made available under aCC-BY-NC-ND 4.0 International license.

suppressing LINE1 elements, which is likely mediated by its enhanced mADPr activity and stronger interaction with LMNA. 


\section{DISCUSSION}

We demonstrated that a novel rare variant of SIRT6 discovered in a cohort of centenarians confers beneficial effects on SIRT6 protein function. centSIRT6 performed better at stimulating DNA repair, mitigating DNA damage, suppressing LINE1 transposons and killing cancer cells. Rare genetic variants are more likely to be deleterious than beneficial (Nelson, Wegmann et al., 2012), and are often associated with human disease. The only other coding SIRT6 human mutation, which had been functionally characterized, leads to embryonic lethality (Ferrer et al., 2018). SIRT6 activity is highly correlated with aging and it has been demonstrated that overexpression of SIRT6 results in increased lifespan in mice (Kanfi et al., 2012, Roichman et al., 2021). It has also been reported that SIRT6 from long-lived species can confer increased longevity in drosophila (Tian et al., 2019). Our findings suggest that increased SIRT6 activity also benefits human longevity.

Genetic association tests on human extreme longevity are uniquely challenging given the rarity of individuals and the lack of reliable statistical power to detect small effects. To date only two variants near APOE and FOXO3a have been associated with longevity in genome-wide scans (Broer, Buchman et al., 2015, Deelen, Beekman et al., 2011). For FOXO3a, this required a large-scale meta-analysis involving 6,036 longevity cases and 3,757 controls (Broer et al., 2015). Since there simply are insufficiently large numbers of centenarians in human populations, genetic association has limited utility in finding loci that promote healthy aging and longevity. In this study, we instead took a candidate SNP approach for SIRT6 within a genetically isolated population of Ashkenazi Jews who exhibited extreme phenotype (>100 years old). The observed association for rs350845 which is linked to higher SIRT6 levels is nominally significant $(\mathrm{P}=$ 0.049). This association between higher SIRT6 expression and longevity is consistent with the data from Drosophila (Tian et al., 2019) and mouse (Kanfi et al., 2012) where SIRT6 overexpression resulted in lifespan extension. The missense variant centSIRT6 had twice the allele frequency in the $\mathrm{AJ}$ centenarians (1\%) compared to controls $(0.5 \%)$, however, we lacked power to detect statistically significant differences $(\mathrm{P}=0.3)$. To further validate this finding, a follow up analysis of the GnomAD cohort of cohorts, which also contains AJ individuals, showed evidence of centSIRT6 enrichment among 75+ year-olds compared to all age groups. In addition to enrolling larger centenarian cohorts, future work may investigate epistasis and the cooccurrence of other SNPs in the genome with centSIRT6 and extreme longevity. 
While increased SIRT6 activity correlates with longer lifespan in model organisms (Kanfi et al., 2012), (Tian et al., 2019), it has not been clear which of SIRT6's enzymatic activities are central to longevity. The seemingly contradictory nature of the centenarian SIRT6 allele possessing decreased deacetylase activity came as an unexpected result. SIRT6 KO mice show several progeroid phenotypes and do not typically survive past 30 days (Mostoslavsky et al., 2006). In these mice, both the deacetylase activity and ribosylase activity are abrogated. In this study we have demonstrated that a centSIRT6 possesses a reduced deacetylase activity in vitro and showed non-discernable differences in vivo. The latter difference likely results from additional protein factors or PTMs present in vivo that help maintain SIRT6 deacetylation activity at close to the wild type levels, despite the weakened core enzyme. Interestingly, loss of SIRT6 deacetylation activity in humans or SIRT6 knockout in monkey lead to severe developmental phenotypes rather than premature aging, suggesting that, at least in primates, deacetylation activity of SIRT6 is required for development but not necessarily for adult longevity (Ferrer et al., 2018, Zhang, Wan et al., 2018).

The extent to which ADP-ribosylation functions of SIRT6 contribute to longevity remains largely unknown. Herein we report that the centSIRT6 allele displays significantly enhanced ribosylation activity against itself and PARP1 in vitro and also appeared enhanced in vivo. Further, we show that centSIRT6 confers improved aspects of SIRT6 function to living cells, including DNA DSB repair, LINE1 element suppression, and tumor cell suppression, all of which showed dependence on SIRT6 ADP-ribosylation functions previously. These results suggest that enhancement of ADP-ribosylation functions of SIRT6 contributes to increased longevity. While we cannot rule out that other aspects of SIRT6 activity, such as glucose metabolism and telomere maintenance, have been impacted by these mutations and may also play a role in the pro-longevity functions of this allele, those effects have been largely attributed to SIRT6 deacetylase activity which appears similar or reduced compared to the WT allele. It remains possible that SIRT6 ADP-ribosylation may play unanticipated roles in these processes as supported by recent reports of SIRT6 ADP-ribosylation of SMARCA2 and KDM2A (Rezazadeh, Yang et al., 2020, Rezazadeh, Yang et al., 2019). Consistent with this idea, SIRT6 mono-ADP ribosylation (and subsequent activation) of PARP1 plays a critical role in DNA DSB repair by facilitating recruitment of DNA repair proteins, such as MRN complex proteins (Haince, McDonald et al., 2008, Van Meter et al., 2016). Improvements in DSB repair efficiency, 
specifically those driven by SIRT6 activity, have been shown to correlate with longevity and healthspan (Roichman, Kanfi et al., 2017, Tian et al., 2019). Additionally, the ribosylation of KAP1 by SIRT6 and subsequent recruitment to transposable elements plays a critical role in silencing these opportunistic elements, which have been linked to age-related sterile inflammation and DNA damage (De Cecco, Ito et al., 2019, Simon et al., 2019, Van Meter et al., 2014). These same elements have been linked to inflammation driven by senescent cells, which are prevalent in aged systems (De Cecco et al., 2019). Further investigation of separation of function alleles of SIRT6 will be required to disentangle the contribution of its deacetylase/deacylase and ADP-ribosylation activities. Beyond its enhanced mADPr activity, centSIRT6 displays enhanced interaction with the nuclear scaffold protein LMNA. This result is especially significant for several reasons. LMNA functions as a key organizer of the nucleus, especially in maintaining heterochromatin at the nuclear periphery and LINE1 elements reside within lamina-associated domains (LADs) (Peric-Hupkes, Meuleman et al., 2010, Zullo, Demarco et al., 2012). Aberrant processing of LMNA results in human premature aging syndrome, Hutchison Gilford Progeria, while LMNA SNPs have been identified in human centenarians (Conneely, Capell et al., 2012, De Sandre-Giovannoli et al., 2003, Eriksson et al., 2003). Fibroblasts isolated from centenarians were also shown to have increased levels of preLMNA, suggesting that modulated functions of LMNA are associated with both premature aging and exceptional longevity (Ghosh et al., 2015, Lattanzi, Ortolani et al., 2014) found that the catalytic domain of SIRT6 interacts with LMNA. In addition, they found that many key aspects of SIRT6 activity, such as PARP1 ribosylation and activation, as well as chromatin localization in response to DNA damage were lost in $\mathrm{LMNA}^{-/}$MEFs. Our data suggest that a gain of function of SIRT6 may have the opposite effect of progerin on longevity. Remarkably, SNPs in LMNA were found in centenarians (Conneely et al., 2012). Fibroblasts isolated from centenarians were also shown to have increased levels of pre-LMNA, suggesting that modulated functions of LMNA are associated with both premature aging and exceptional longevity (Lattanzi et al., 2014).

In summary, we demonstrated that centSIRT6 displays reduced deacetylation activity in vitro, and has enhanced mADPr activity both in vitro and in vivo. This change in the balance of the two enzymatic activities leads to enhanced function of SIRT6 in DNA repair, LINE1 suppression and cancer cell killing, which are the activities that require mADPr activity of 
SIRT6. centSIRT6 also shows enhanced binding to LMNA which may further promote its function in DNA repair and chromatin organization via direct stimulation of SIRT6 enzymatic activity, and by coordinating interactions of LMNA with other components of LMNA complex (Fig 7). It would be interesting to model centSIRT6 in mice, to directly test whether this allele extends lifespan. However, the C-terminus of SIRT6 which harbors the centenarian mutations is not conserved in the mouse. SIRT6 and LMNA pathways are highly linked with the aging process, indicating that the SIRT6 ribosylation activity may be the more critical of the two enzymatic functions in regards to healthy aging and may aid LMNA to organize/control nuclear protein-protein and protein-RNA interactions. Given these results, there may be a benefit to enhancing SIRT6 activity, specifically the ribosylase activity. Molecules that impact SIRT6 activity, as well as its major co-enzyme NAD+, have been identified and hold potential as future methods of anti-aging interventions (Li, Bonkowski et al., 2017, Rahnasto-Rilla, Tyni et al., 2018, Rajman, Chwalek et al., 2018). Further refining the search for interventions that specifically target the mADPr activity of SIRT6 may yield more specific therapeutics to improve lifespan and healthspan.

\section{MATERIALS AND METHODS}

\section{Human subjects}

Ashkenazi Jewish population derived from an undetermined small number (estimated to be in the several thousands) of founders. External factors, including ecclesiastical edicts prohibiting all social contact with Jews, the Crusades, the establishment of the Pale of Settlement, numerous Pogroms, and ethnic bigotry, resulted in the social isolation and inbreeding of the Ashkenazi Jews. This history resulted in both cultural and genetic homogeneity and has made this population useful for identification of genetic traits. In our study, a centenarian is defined as a healthy individual living independently at 95 years of age or older and a control is defined as an individual without a family history of unusual longevity; parents of controls survived to the age of 85 years or less. The participants' ages were defined by birth certificates or dates of birth as stated on passports. This study group consisted of 496 Ashkenazi Jewish centenarians and 572 Ashkenazi Jewish controls that were previously collected as part of longevity study at the Albert Einstein College of Medicine (Barzilai et al, JAMA, 2003). 
Informed written consent was obtained in accordance with the policy of the committee on clinical investigations of the Albert Einstein College of Medicine, New York, NY. An additional 5,185 AJ controls were derived from GnomAD data base.

\section{Cell lines}

HEK293 SIRT6 overexpression lines were generated by transfecting HEK293 cells with linearized CMV-SIRT6 plasmids via jetPRIME transfection reagent and selecting stably integrated clones. To generate normal human fibroblasts expressing WT and centenarian alleles of SIRT6 under control of cumate-inducible promoter (cumate SIRT6 fibroblasts), constructs containing SIRT6 alleles under control of cumate promoter were integrated in the genome of telomerase-immortalized SIRT6-KO human HCA2 foreskin fibroblasts via the PiggyBac Transposon Vector System. Endogenous SIRT6 was knocked out in these cells using CRISPR/Cas-9 (Tian et al., 2019). NHEJ and HR reporter assays were conducted using telomerase-immortalized HCA2 human fibroblast cell lines containing integrated reporter constructs (I9A and H15C) (Mao et al., 2008, Seluanov et al., 2010). HT1080 and HeLa cell lines were used to assess anti-tumor activity. Human H7 ESCs (WiCell Research) and their genetic modified derivatives were maintained on Matrigel in mTeSR Plus medium and used to generate MSCs.

\section{Cell culture}

All cell lines were maintained in humidified incubators at $5 \% \mathrm{CO}_{2}, 5 \% \mathrm{O}_{2}$, at $37^{\circ} \mathrm{C}$. Cells were grown in Eagle's minimum essential medium with 15\% fetal bovine serum and $1 \mathrm{x}$ penicillin/streptomycin, with the exception of the HEK293, HT1080 and HeLa cells, which were culture in DMEM with D-Glucose and L-Glutamine. Human MSCs were cultured on Gelatincoated plate in hMSC culture medium ( $\alpha$ MEM (Gibco), 10\% fetal bovine serum (GeminiBio), $1 \%$ penicillin/streptomycin (Gibco) and $1 \mathrm{ng} / \mathrm{mL}$ bFGF (ThermoFisher)). The cell lines are routinely tested for mycoplasma contamination.

\section{Sequencing of SIRT6 gene in Ashkenazi Jewish Centenarians}

The sequencing of SIRT6 gene was a part of the pooled target capture sequencing (capture-seq) project aiming to discover centenarian-enriched rare variants in genes involved in conserved longevity assurance pathways (Ryu, Han et al., 2018). SIRT6 was selected as a candidate longevity-associated gene. All SIRT6 variants discovered in the capture-seq of 1,068 AJ samples (496 centenarians vs. 572 controls) are provided in Table I. 
Plots of SIRT6 expression and eQTL status for rs350845 were downloaded from the GTEx website.

\section{GnomAD centSIRT6 enrichment}

GnomAD analysis was performed on the 2.1.1 release of combined exome and wholegenome sequences representing 125,748 exomes and 15,708 whole genomes. Chromosome 19 variants were downloaded from the GnomAD database, and since the centSIRT6 allele is rare $(0.5 \%-1 \%)$ we filtered for SNPs between $0.1 \%$ and $1 \%$ frequency. Our goal was to build a distribution of allele occupancy at the 75+ age group normalized against all age groups. While this is not a traditional association study per se, it does allow us to witness allele frequency bias in older vs. younger age brackets.

$$
\text { Normalized over } 75 \text { allele counts }=\frac{\text { allele counts in over } 75}{\text { allele counts all ages }}
$$

A normalized value of 0 represents a complete absence of the allele in $75+$, and higher values represent greater occupancy of that allele in the 75+ age bracket compared to all ages. Alleles with a value of 1 were filtered from consideration, as these may have represented alleles only observed in cohorts comprised of older individuals. In total 66,441 SNPs were measured, of which 3,307 were missense.

\section{Gene editing at SIRT6 locus}

CRISPR/Cas9-mediated knock-in was performed using Alt-R CRISPR-Cas9 System (IDT) and HDR Donor Oligos. Cas9 nuclease, sgRNA (GAATCTCCCACCCGGATCAA) targeting double variant site and single-strand DNA oligo donors (ssODNs) containing SIRT6 double variant were ordered from IDT. To generate SIRT6 double variant knock-in hESCs, $2 \times 10^{\wedge} 5$ individualized $\mathrm{hESCs}$ were resuspended in $10 \mu \mathrm{L}$ Resuspension Buffer $\mathrm{R}$ (Invitrogen) containing CRISPR ribonucleoproteins (Cas9 protein+sgRNA) and ssODNs and were then electroporated using NEON Transfection System (Invitrogen). After electroporation, cells were seeded on Matrigel-coated plates in mTeSR Plus with 1x RevitaCell Supplement (Gibco). After 48h expansion, cells were dissociated by Accutase and 10,000 cells were seeded on CytoSort ${ }^{\mathrm{TM}}$ Array (10,000 microwells, CELL Microsystem). Once cells were attached, microwells containing single colony were automatically picked and transferred to 96-well plate by CellRaft AIR System (CELL Microsystem). The expanded clones on 96-well plate were further 
genotyped by TaqMan genotyping assay (rs201141490, rs 183444295, ThermoFisher) and Sanger sequencing.

\section{MSC differentiation}

hESCs-derived embryoid bodies were first produced using AggreWell (Stem Cell technology) and were then plated on Matrigel-coated plates in hMSC differentiation medium ( $\alpha$ MEM (Gibco), 10\% fetal bovine serum (GeminiBio), 1\% penicillin/streptomycin (Gibco), 10 $\mathrm{ng} / \mathrm{mL}$ bFGF (ThermoFisher) and $5 \mathrm{ng} / \mathrm{mL}$ TGF $\beta$ (Thermofisher)) for around 10 days till fibroblast-like cells were confluent. These fibroblast-like cells were maintained in hMSC culture medium on Gelatin-coated $10 \mathrm{~cm}$ dishes for two passages and were further sorted by FACS machine (BD FACS Aria II) to purify CD73/CD90/CD105 tri-positive hMSCs.

\section{Western blotting}

Cells and reactions were collected using a 2x Laemmli solution and incubated on ice for $15 \mathrm{~min}$, during which time the samples were passed through a large gauge needle several times and vortexed every $5 \mathrm{~min}$. Samples were then spun at 14,000 RPM to remove debris and the supernatant transferred to a new tube. Samples were heated in boiling water for 20 min before being centrifuged at 14,000 RPM for 1min and loaded into a BioRad Criterion 4-20\% gel. After transfer to PDVF membrane and blocked (5\% dehydrated milk) for $2 \mathrm{hr}$ at RT, membranes were incubated overnight antibodies in $2.5 \%$ blocking buffer at $4^{\circ} \mathrm{C}$. Membranes were washed $3 \mathrm{x}$ with TBST for 10 min each before secondary antibody in 1x TBST was added for $2 \mathrm{hr}$ incubation at RT. Membranes were washed 3x with TBST for 10 min and then imaged.

The following antibodies were used: H3 (Abcam ab500)-1:5000, H3K9ac (Abcam ab4441)1:1000, H3K18ac (Abcam ab1191)-1:1000, $\beta$-tubulin (Abcam ab6046)-1:10,000, SIRT6 (Cell Signaling \#12486)-1:1000, Lamin A/C-1:1000 (Abcam ab108595, Millipore 05-714), $\gamma \mathrm{H} 2 \mathrm{AX}$ (Millipore 05-636), PARP1(Abcam ab227244)-1:1000, mADPr 1:500 (AbD33204 and AbD33205)(Bonfiglio et al., 2020).

\section{Immunoprecipitation}

Cells were plated and grown with equivalent dosages of cumate for $48 \mathrm{hrs}$ prior to IP. In brief, cells were collected via trypsin and centrifugation and then lysed on ice using IP Buffer (20 mM HEPES pH=8, $0.2 \mathrm{mM}$ EDTA, 5\% glycerol, $150 \mathrm{mM} \mathrm{NaCl,} \mathrm{1 \%} \mathrm{NP40)} \mathrm{+} \mathrm{COMplete}$ protease inhibitor for $10 \mathrm{~min}$. Lysate was sonicated at $25 \%$ output for 10 pulses and then debris pelleted by centrifugation at $4^{\circ} \mathrm{C}$ at $13000 \mathrm{RPM}$ for $10 \mathrm{~min}$. Supernatant was transferred to a new 
tube and precleared with $\mathrm{A} / \mathrm{G}$ Sepharose beads at $4^{\circ} \mathrm{C}$ for $1 \mathrm{hr}$ on a rotator. Beads were removed by centrifugation and transfer of cleared sample to new tubes. $50 \mu 1$ of sample was reserved as input control. Samples were incubated overnight at $4^{\circ} \mathrm{C}$ with $3 \mu \mathrm{g}$ of antibody (SIRT6-Cell Signaling) \#12486; PARP1-Abcam ab227244; Lamin A/C-Millipore 05-714; AbD33204(Bonfiglio et al., 2020), AbD33205(Bonfiglio et al., 2020), then with $30 \mu$ of 25\% Sepharose for $2 \mathrm{hr}$ at $4^{\circ} \mathrm{C}$. Samples were spun down and beads washed 5x with IP buffer. Final resuspension with $100 \mu \mathrm{l}$ IP buffer.

\section{DNA Repair Assays}

Both NHEJ and HR efficiency were assessed as previously described(Seluanov et al., 2010). In brief, I-Sce1, SIRT6 or HPRT control, and dsRED plasmid were transfected into telomerase-immortalized human foreskin fibroblasts containing chromosomally integrated NHEJ or HR reporter cassettes (I9A or H15C) cells (Mao et al., 2008). Cells were allowed 3 days to recover prior to analysis by flow cytometry. Efficiency was calculated as the ratio of GFP events over dsRED events.

\section{Transfections}

Transfections were carried out by plating cells at a density of 500,000 cells $/ 10 \mathrm{~cm}$ plate two days prior to transfection. Transfections were carried out using the Amaxa Nucleofector with Normal Human Dermal Fibroblast transfection solution following manufacture's protocol. For cancer cell transfections, jetPRIME transfection reagent was used to deliver plasmids into cells.

\section{Quantitative RT-PCR}

Total RNA was isolated from cells at $80 \%$ confluence using Trizol Reagent and then treated with DNase. cDNA was synthesized using Superscript III (Life Technologies) cDNA kit with the OligodT primer. qRT-PCR was performed on the BioRad CFX Connect Real Time machine with SYBR Green Master Mix (BioRad) using $30 \mathrm{ng}$ of cDNA per reaction with 3x reactions/sample. All primer sets were tested for specificity and efficiency. Actin was assayed using QuantumRNA Actin Universal primers (Thermo AM1720). LINE1 ORF1 FwdATGGCGAAAGGCAAACGTAAG， Rev-ATTTTCGGTTGTGTTGGGGTG； LINE1 ORF2 Fwd GCAGGGGTTGCAATCCTAGTC, Rev- CTGGGTGCTCCTGTATTGGGT.

\section{Immunofluorescence and apoptosis}


$\gamma \mathrm{H} 2 \mathrm{AX}$ and 53BP1 immunostaining was carried out as previously described(Mao et al., 2011). Anti- $\gamma \mathrm{H} 2 \mathrm{AX}(05-636)$ and anti-53BP1 (MAB3804) antibodies were purchased from Millipore. Apoptosis in fibroblasts was measured using the Annexin V Staining Kit (Roche).

\section{MMS treatment}

$3 \times 10^{4} \mathrm{hMSCs}$ were seeded on gelatin-coated 96-well plate and hMSCs were treated with DNA-damaging agents for 48 hours upon reaching 90\% confluence. CellTiter 96 AQueous One Solution Cell Proliferation Kit (MTS assay, Promega) was used to measure cell viability according to the manufacturer's protocol. DNA-damaging agents employed in this assay were as follows: Methyl methanesulfonate (0.125/0.25/0.5 mM, MMS).

\section{Gamma Irradiation}

Cells were grown to $75 \%$ confluency prior to treatment on coated slides. A Cs-137 irradiator was used to deliver $2 \mathrm{~Gy}$ of radiation to cells. Cells were transported in a $37^{\circ} \mathrm{C}$ container and media was replaced post exposure.

\section{Paraquat Treatment}

Cells were maintained to $75 \%$ confluency, at which point fresh media lacking sodium pyruvate and containing paraquat was added. Cells were maintained for $24 \mathrm{hrs}$ in treated media, followed by replacement with fresh media lacking sodium pyruvate. $48 \mathrm{hrs}$ post treatment, the cells stained and evaluated for apoptosis.

\section{SIRT6 Protein Purification}

His-tagged SIRT6 cDNA was cloned into pET11a vectors and transformed into RosettaGami E. coli cells. Cells were grown in presence of antibiotics and then protein production was induced with $0.5 \mathrm{mM}$ IPTG $2 \mathrm{hrs}$ before harvest. Cells were spun down and lysed on ice for $1 \mathrm{~h}$ using a in a solution of $50 \mathrm{mM}$ Tris- $\mathrm{HCl}(\mathrm{pH}=7.5), 300 \mathrm{mM} \mathrm{NaCl}, 10 \%$ glycerol, and $10 \mathrm{mM}$ imidazole with EDTA-free protease inhibitor (Sigma \#P8849) and 1mg/ml egg white lysozyme followed by sonication with a Branson instrument. After removal of cell debris by centrifugation, lysate was incubated with $\mathrm{Ni}_{2}{ }^{+}$-NTA agarose overnight. Solution with beads was placed in gravity column and washed with lysis solution, followed by 2 volumes of wash buffer (lysis buffer $+30 \mathrm{mM}$ imidazole). Finally, protein was eluted with elution buffer (lysis buffer +500 $\mathrm{mM}$ imidazole) and fractions were collected. Protein concentration was assessed by BCA assay and run on an SDS-page gel. The 3-4 highest concentration fractions were pooled and dialyzed against storage buffer (50 mM Tris- $\mathrm{HCl}$ pH=7.5, $150 \mathrm{mM} \mathrm{NaCl}, 1 \mathrm{mM} \mathrm{DTT}, 5 \%$ glycerol). 


\section{Stable Isotope Labeling of Amino Acids in Cell Culture (SILAC)}

Turnover experiments were performed using HEK293 cell lines stably expressing SIRT6 WT or centSIRT6. Cells were cultured for one week until confluent in MEM for SILAC (Thermo) supplemented with $10 \%$ dialyzed FBS (Gibco), L-glutamine, L-arginine ${ }^{13} \mathrm{C}_{6}{ }^{15} \mathrm{~N}_{4}$ (Cambridge Isotopes), and L-lysine ${ }^{13} \mathrm{C}_{6}{ }^{15} \mathrm{~N}_{2}$ (Cambridge Isotopes). The media was changed to normal culture medium and cell pellets were harvested at $0,2,4,6,8,12, \& 24$ hours post-media change. Cell pellets were lysed in buffer containing $8 \mathrm{M}$ urea, $75 \mathrm{mM} \mathrm{NaCl}, 50 \mathrm{mM}$ Tris, pH 8.5, with protease inhibitor cocktail (Roche). Pellets were vortexed for 30s and sonicated 5x $10 \mathrm{~s}$ with $1 \mathrm{~min}$ rest on ice in between sonication steps. Lysate was centrifuged at 15,000 xg for $10 \mathrm{~min}$ and then supernatant was collected.

\section{SIRT6 deacylation activity}

The substrate for this reaction is a synthetic TNF-derived peptide first developed by Schuster et al (Schuster, Roessler et al., 2016) was synthesized by Genscript. Reactions were performed with $150 \mathrm{mM} \mathrm{NaCl}, 20 \mathrm{mM}$ Tris, 5\% glycerol, $1 \mathrm{mM} \beta$-mercaptoethanol, $2 \mu \mathrm{M}$ SIRT6, and substrate concentration ranges of 7-1000 $\mu \mathrm{M} \mathrm{NAD}^{+}$and 2-88 $\mu \mathrm{M}$ peptide. Reactions were performed at $37^{\circ} \mathrm{C}$ and fluorescence was measured using 310/405 nm excitation/emission spectra on a Tecan Spark 20M plate reader. Readings were taken every 30s and initial rates were calculated from the relative fluorescence increase over a minimum of $6 \mathrm{~min}$.

\section{Histone Analysis}

Histones were purified from cumate SIRT6 fibroblasts (SIRT6 KO primary human foreskin fibroblasts constitutively expressing the catalytic subunit of telomerase as well as various alleles of SIRT6 via a cumate-inducible promoter) using an established acid extraction method followed by propionylation of lysines prior to trypsin digestion to enhance coverage (Shechter, Dormann et al., 2007, Sidoli et al., 2016). A data-independent analysis (DIA) mass spectrometry (MS) method was employed for quantitation of modified peptides after samples were separated by nano-LC using EpiProfile(Sidoli, Lin et al., 2015) or, alternatively, after direct infusion followed by a one-minute acquisition and analysis with EpiProfileLite (Sidoli, Kori et al., 2019).

\section{Analysis of SIRT6 and LMNA protein-protein interactions by mass spec}

Cumate SIRT6 fibroblasts were used to compare interactomes for centSIRT6 and the wild type SIRT6. Nuclear extracts were prepared using hypotonic lysis buffer. Nuclei isolated 
from approximately $2.5 \times 10^{7}$ cells were resuspended in one $\mathrm{ml}$ of extraction buffer $(50 \mathrm{mM}$ TrisHCl pH 7.5, $150 \mathrm{mM} \mathrm{NaCl}, 10 \%$ glycerol, $5 \mathrm{mM}$ DTT, 0.25\%NP-40, 1x Roche Complete protease inhibitors, as well as kinase/phosphatase inhibitors- $1 \mathrm{mM}$ NaVO4, 10mM betaglycerophosphate, $1 \mathrm{mM}$ sodium pyrophosphate, $1 \mathrm{mM} \mathrm{NaF}$ ) and nuclei were disrupted by passage through a 27 gauge needle followed by sonication ( 3 pulses at constant $20 \%$ power) with a Branson Sonifier on ice. Next, samples were filtered through $0.2 \mu \mathrm{m}$ MWCO filter to remove any insoluble material (and reduce non-specific binding). Proteins were quantified using the BCA assay and equal amount of wild type SIRT6 and centSIRT6 derived extract were divided into 5 replicates each. Three replicates of extract received $4 \mu \mathrm{g}$ of anti-SIRT6 antibody (Cell Signaling \#1248) or anti-LaminA (Lamin A/C-Millipore 05-714) and $75 \mu$ l of Miltenyi protein G $\mu \mathrm{MACS}$ magnetic particles. Two of the replicates were mixed with normal rabbit IgG (Cell Signaling \#2729) as controls for non-specific binding to the particles. Samples were rotated at $4^{\circ} \mathrm{C}$ for $6 \mathrm{~h}$ followed by separation by the magnet. Samples were washed with 3 additional $\mathrm{ml}$ of extraction buffer and eluted with $100 \mu \mathrm{l}$ of boiling elution buffer (5\% SDS with $50 \mathrm{mM}$ TrisHCl $\mathrm{pH}$ 7.5). After removal of SDS with S-columns (Protifi; Huntington, NY) and trypsin digestion, peptides were resuspended in MS-grade water and labeled with tandem mass tags (TMT 10-plex; Thermo Fisher). Samples were resolved by nano-electrospray ionization on an Orbitrap Fusion Lumos MS instrument (Thermo) in positive ion mode using a $30 \mathrm{~cm}$ home-made column packed with $1.8 \mu \mathrm{m} \mathrm{C}-18$ beads to resolve the peptides. Solvent A was $0.1 \%$ formic acid and solvent B was $100 \%$ acetonitrile (CAN) with $0.1 \%$ formic acid. The length of the run was $2 \mathrm{~h}$ with a 90 min gradient. CID (35\% collision energy) was used for MS2 fragmentation. HCD (60\% collision energy) was used for MS3 detection of TMT groups. Other details of the run parameters may be found in the embedded run report of the RAW data file uploaded to the ProteomeXchange database. Peptide assignments were made using Proteome Discoverer and Sequest and MS3 ions were used for quantitation. False discovery rates (FDR) were estimated using a Decoy Database Search with Target FDR (strict) set to 0.01 and Target FDR (relaxed) set to 0.05. Validation was based on q-value. In the consensus step, ions with a co-isolation threshold above $30 \%$ were excluded. Normalization between replicates was achieved using the total protein approach (Wisniewski, 2017) where peptide counts for a single protein were divided by the sum of all proteins in the lane. Proteins appearing in specific antibodies (either anti-SIRT6 or anti-Lamin A) compared to normal IgG serum with Student $t$-test $p<0.05$ ) were 
considered as interactions. Similarly, proteins showing higher levels in centSIRT6 versus wild type SIRT6 were based upon $p<0.05$.

\section{SIRT6-NAD ${ }^{+}$binding by Tryptophan Fluorescence}

One $\mu \mathrm{M}$ of SIRT6 protein in $50 \mu \mathrm{l}$ of buffer $(50 \mathrm{mM}$ TrisHCl $\mathrm{pH}=7.5$ and $150 \mathrm{mM} \mathrm{NaCl})$ was combined with a range of $\mathrm{NAD}^{+}(0-2 \mathrm{mM})$. Samples were then placed in a 384 Corning Flat Black plate and analyzed in a Tecan Spark 20M plate reader. Fluorescence was measured across $300-400 \mathrm{~nm}$ range in $2 \mathrm{~nm}$ steps using a $280 \mathrm{~nm}$ excitation. Background quenching by $\mathrm{NAD}^{+}$of SIRT6 denatured by 7M urea was subtracted from the spectra as described previously(Pan, Muino et al., 2011).

\section{Deacetylase Assay}

Three $\mu \mathrm{g}$ of SIRT6 protein was combined with $0.5 \mu \mathrm{g}$ histones, 1 or $5 \mathrm{mM} \mathrm{NAD}^{+}, 30 \mathrm{mM}$ Tris- $\mathrm{HCl} \mathrm{pH}=8,4 \mathrm{mM} \mathrm{MgCl} 2,1 \mathrm{mM}$ DTT and $\mathrm{ddH}_{2} \mathrm{O}$ up to $50 \mu \mathrm{l}$. Designer nucleosomes with relevant PTMs were obtained from Epicypher. All reagents were prepared on ice and moved to $37^{\circ} \mathrm{C}$ for the duration of the incubation. Reaction was quenched with direct application of 1 volume of 2x Laemmli buffer with BME. Samples were boiled for 15 min before being run in Western analysis using anti-H3K9ac and anti-H3K18ac antibodies.

\section{PARP1 Ribosylation Assay}

Five $\mu \mathrm{g}$ of SIRT6 protein was combined with $100 \mathrm{fm}$ PARP1, $20 \mathrm{mM}$ Tris- $\mathrm{HCl} \mathrm{pH}=8,10$ $\mu \mathrm{M} \mathrm{ZnCl}_{2}, 10 \mu \mathrm{M} \mathrm{MgCl}_{2}, 10 \%$ glycerol, $300 \mu \mathrm{M} \mathrm{NAD}^{+}, 1 \mathrm{mM}$ DTT, $0.1 \mu \mathrm{g} / \mathrm{ml}$ salmon sperm DNA and $\mathrm{ddH}_{2} \mathrm{O}$ up to $50 \mu \mathrm{l}$. All reagents were prepared on ice and moved to $30^{\circ} \mathrm{C}$ for $30 \mathrm{~min}$. Reaction was quenched with direct application of 1 volume of 2x Laemmli buffer with BME. Samples were boiled for $15 \mathrm{~min}$ before being run in Western analysis using anti-PADPR antibody.

\section{SIRT6 Ribosylation Assay}

Three $\mu \mathrm{g}$ of SIRT6 was combined with $50 \mathrm{mM}$ Tris-HCl pH=7.5, $1 \mathrm{mM}$ DTT, $10 \mu \mathrm{M}$ $\left.\mathrm{ZnCl}_{2}, 150 \mathrm{mM} \mathrm{NaCl}, 25 \mathrm{uM} \mathrm{NAD}{ }^{+}, 1 \mu{ }^{32} \mathrm{P}\right]-\mathrm{NAD}^{+}(800 \mathrm{Ci} / \mathrm{mmol}, 5 \mathrm{mCi} / \mathrm{ml}$; Perkin Elmer BLU023x250UC) and $\mathrm{ddH}_{2} \mathrm{O}$ up to $20 \mu \mathrm{l}$. All reagents were combined on ice in a master mix except for SIRT6. Master mix was aliquoted into reaction tubes and SIRT6 was added and incubated at $37^{\circ} \mathrm{C}$ for $3 \mathrm{~h}$. Reaction were quenched with 1 volume of $2 \mathrm{x}$ Laemmli buffer with BME. Samples were boiled and then run on SDS-PAGE gel and then transferred to PDPF membrane. Self-ribosylation was assayed using phosphoimager. 


\section{Thermostability}

Four $\mu \mathrm{M}$ SIRT6 protein was combined with 1x SYPRO Orange dye in storage buffer (50 $\mathrm{mM}$ Tris- $\mathrm{HCl} \mathrm{pH}=7.5,150 \mathrm{mM} \mathrm{NaCl}, 1 \mathrm{mM}$ DTT, 5\% glycerol) to $50 \mu \mathrm{l}$. Samples were placed in qRT-PCR plate and run on a BioRad CFX Connect Real Time machine using a Melt Curve protocol $\left(30^{\circ} \mathrm{C}-75^{\circ} \mathrm{C}, 0.5^{\circ} \mathrm{C}\right.$ steps in $10 \mathrm{~s}$ intervals $)$.

\section{FRET}

Mutagenesis to generate the centenarian mutant (N308K/A313S) was performed using NEB Q5 site-directed mutagenesis kit, following protocols for primer design.

HEK293-6E cells were transfected using 293fectin protocol (Thermo Fisher). The SIRT6 biosensors were expressed using mammalian expression vector pTT5 (National Research Council, Canada). After two days in culture, approximately 30 million were produced, generating transiently transfected cell lines expressing the biosensor at high levels. The cell line was maintained using F17 medium (Sigma) + (200nM/mL) GlutaMAX.

On each day of FRET assays, approximately 30 million cells from each transfection were harvested, washed three times in PBS with no Mg or Ca (Thermo Scientific; Waltham, MA) by centrifugation at $300 \mathrm{x} \mathrm{g}$, filtered using 70- $\mu \mathrm{m}$ cell strainers (Corning; Corning, NY), and diluted to 1-2 million cells/mL using a Countess ${ }^{\mathrm{TM}}$ Automated cell counter (Invitrogen; Carlsbad, CA). On each day of experiments, cell viability was assessed using the trypan blue assay. After resuspension and dilution in PBS, the cells were continuously and gently stirred with a magnetic bar at room temperature to keep the cells in suspension and prevent clumping.

An in-depth description of the fluorescence instrumentation has been published previously(Schaaf, Peterson et al., 2017). For FLT measurements, the observed fluorescence waveform was convolved with the instrument response function to determine $F(t)$ Eq.1, the average energy transfer efficiency $\mathrm{E}$ was calculated from the average FLTs of donor $\tau_{D}$ and donor-acceptor, $\tau_{D A}$, using Eq. 2, and the donor-acceptor distance R was calculated using Eq. 3.

\begin{tabular}{|l|l|}
\hline$F(t)=\sum_{i=1}^{2} A_{i} \exp \left(-t / \tau_{i}\right)$ & (Eq. 1$)$ \\
\hline$F R E T E=1-\frac{\tau_{\mathrm{DA}}}{\tau_{\mathrm{D}}}$ & (Eq. 2$)$ \\
\hline $\mathrm{R}=\mathrm{R}_{0}[(1 / \mathrm{E})-1]^{1 / 6}$ & (Eq. 3$)$ \\
\hline
\end{tabular}




\section{Statistics}

Unless otherwise noted, the Student's $t$-test was used to determine statistical significance between groups. All tests were two-tailed and $p$-values were considered significant below a 0.05 threshold. Cell culture experiments utilized at least two separately derived cell lines for each genotype and were performed in triplicate unless noted otherwise. In vitro assays were done in triplicate using two or more separate protein isolation preps.

\section{DATA AVAILABILITY}

\section{Lead Contact}

Further information and requests for resources and reagents should be directed to and will be fulfilled by the lead contact, Vera Gorbunova (vera.gorbunova@ rochester.edu)

\section{Materials Availability}

Plasmids and cell lines generated in this study are available upon request

\section{Data and Code Availability}

All data needed to evaluate the conclusions in the paper are present in the paper and/or the Supplementary Materials. All sequencing data have been deposited in the Sequence Read Archive (SRA) under the bioproject number PRJNA669033, PRJNA669034 and PRJNA669037. MS data files will be uploaded to PRIDE/ProteomeXchange data repository and the Digital Object Identifier number will be provided prior to publication.

\section{Supplementary Data}

Data S1: Mass spectrometry data for histone PTM quantification

Data S2: Mass spectrometry data for SIRT6 interacting proteins

Data S3: Mass spectrometry data for LMNA interacting proteins

\section{ACKNOWLEDGEMENTS}

We would like to extend a special thanks to Dr. Ivan Matic for providing the mADPr antibodies. We are thankful to Kevin Welle, Jennifer Hryhorenko of Mass Spectrometry 
bioRxiv preprint doi: https://doi.org/10.1101/2021.12.13.472381; this version posted December 13, 2021. The copyright holder for this preprint (which was not certified by peer review) is the author/funder, who has granted bioRxiv a license to display the preprint in perpetuity. It is made available under aCC-BY-NC-ND 4.0 International license.

Resource Lab for their help and advice. Funding was provided by the US National Institute of Health. 


\section{AUTHOR CONTRIBUTIONS}

Conceptualization: YS, VG, AS, MS,

Methodology: MS, EE, VG, AS, YS

Investigation: MS, JY, JG, TMS, LZ, MG, SLY, AP, MVM, JH, SR, AT, YZ, AH, GA, NB,

AW, KM, BAG, DDT, PDR, SE, MZ, GT, MG, EE

Visualization: MS, VG, AS, YS

Funding acquisition: VG, AS, YS, PDR, BAG

Project administration: VG, AS, YS

Supervision: VG, AS, YS

Writing - original draft: MS

Writing - review \& editing: MS, JY, YS, JV, VG, AS, EE

\section{Conflicts of Interest}

VG serves on the SAB of Genflow and DoNotAge. Other authors declare no competing interests, or other interests that might be perceived to influence the results and/or discussion reported in this paper. 


\section{REFERENCES}

Adolph KW (1987) ADPribosylation of nuclear proteins labeled with [3H]adenosine: changes during the HeLa cycle. Biochim Biophys Acta 909: 222-30

Adolph KW, Song MK (1985) Variations in ADP-ribosylation of nuclear scaffold proteins during the HeLa cell cycle. Biochem Biophys Res Commun 126: 840-7

Beli P, Lukashchuk N, Wagner SA, Weinert BT, Olsen JV, Baskcomb L, Mann M, Jackson SP, Choudhary C (2012) Proteomic investigations reveal a role for RNA processing factor THRAP3 in the DNA damage response. Mol Cell 46: 212-25

Bilan V, Leutert M, Nanni P, Panse C, Hottiger MO (2017) Combining Higher-Energy Collision Dissociation and Electron-Transfer/Higher-Energy Collision Dissociation Fragmentation in a Product-Dependent Manner Confidently Assigns Proteomewide ADP-Ribose Acceptor Sites. Anal Chem 89: 1523-1530

Bonfiglio JJ, Leidecker O, Dauben H, Longarini EJ, Colby T, San Segundo-Acosta P, Perez KA, Matic I (2020) An HPF1/PARP1-Based Chemical Biology Strategy for Exploring ADP-

Ribosylation. Cell 183: 1086-1102 e23

Broer L, Buchman AS, Deelen J, Evans DS, Faul JD, Lunetta KL, Sebastiani P, Smith JA, Smith AV, Tanaka T, Yu L, Arnold AM, Aspelund T, Benjamin EJ, De Jager PL, Eirkisdottir G, Evans DA, Garcia ME, Hofman A, Kaplan RC et al. (2015) GWAS of longevity in CHARGE consortium confirms APOE and FOXO3 candidacy. J Gerontol A Biol Sci Med Sci 70: 110-8 Conneely KN, Capell BC, Erdos MR, Sebastiani P, Solovieff N, Swift AJ, Baldwin CT, Budagov T, Barzilai N, Atzmon G, Puca AA, Perls TT, Geesaman BJ, Boehnke M, Collins FS (2012) Human longevity and common variations in the LMNA gene: a meta-analysis. Aging Cell 11: 475-81

De Cecco M, Ito T, Petrashen AP, Elias AE, Skvir NJ, Criscione SW, Caligiana A, Brocculi G, Adney EM, Boeke JD, Le O, Beausejour C, Ambati J, Ambati K, Simon M, Seluanov A, Gorbunova V, Slagboom PE, Helfand SL, Neretti N et al. (2019) L1 drives IFN in senescent cells and promotes age-associated inflammation. Nature 566: 73-78

De Sandre-Giovannoli A, Bernard R, Cau P, Navarro C, Amiel J, Boccaccio I, Lyonnet S, Stewart CL, Munnich A, Le Merrer M, Levy N (2003) Lamin a truncation in Hutchinson-Gilford progeria. Science 300: 2055

Deelen J, Beekman M, Uh HW, Helmer Q, Kuningas M, Christiansen L, Kremer D, van der Breggen R, Suchiman HE, Lakenberg N, van den Akker EB, Passtoors WM, Tiemeier H, van Heemst D, de Craen AJ, Rivadeneira F, de Geus EJ, Perola M, van der Ouderaa FJ, Gunn DA et al. (2011) Genome-wide association study identifies a single major locus contributing to survival into old age; the APOE locus revisited. Aging cell 10: 686-698

Eriksson M, Brown WT, Gordon LB, Glynn MW, Singer J, Scott L, Erdos MR, Robbins CM, Moses TY, Berglund P, Dutra A, Pak E, Durkin S, Csoka AB, Boehnke M, Glover TW, Collins FS (2003) Recurrent de novo point mutations in lamin A cause Hutchinson-Gilford progeria syndrome. Nature 423: 293-8

Etchegaray JP, Mostoslavsky R (2015) Cell Fate by SIRT6 and TETs. Cell Cycle 14: 2187-8 Ferrer CM, Alders M, Postma AV, Park S, Klein MA, Cetinbas M, Pajkrt E, Glas A, van Koningsbruggen S, Christoffels VM, Mannens M, Knegt L, Etchegaray JP, Sadreyev RI, Denu JM, Mostoslavsky G, van Maarle MC, Mostoslavsky R (2018) An inactivating mutation in the histone deacetylase SIRT6 causes human perinatal lethality. Genes Dev 32: 373-388 
Ghosh S, Liu B, Wang Y, Hao Q, Zhou Z (2015) Lamin A Is an Endogenous SIRT6 Activator and Promotes SIRT6-Mediated DNA Repair. Cell Rep 13: 1396-1406

Gioutlakis A, Klapa MI, Moschonas NK (2017) PICKLE 2.0: A human protein-protein interaction meta-database employing data integration via genetic information ontology. PLoS One 12: e0186039

Haince JF, McDonald D, Rodrigue A, Dery U, Masson JY, Hendzel MJ, Poirier GG (2008) PARP1-dependent kinetics of recruitment of MRE11 and NBS1 proteins to multiple DNA damage sites. J Biol Chem 283: 1197-208

Hendriks IA, Larsen SC, Nielsen ML (2019) An Advanced Strategy for Comprehensive Profiling of ADP-ribosylation Sites Using Mass Spectrometry-based Proteomics. Mol Cell Proteomics 18: 1010-1026

Hirvonen K, Laivuori H, Lahti J, Strandberg T, Eriksson JG, Hackman P (2017) SIRT6 polymorphism rs117385980 is associated with longevity and healthy aging in Finnish men. BMC Med Genet 18: 41

Huttlin EL, Ting L, Bruckner RJ, Gebreab F, Gygi MP, Szpyt J, Tam S, Zarraga G, Colby G, Baltier K, Dong R, Guarani V, Vaites LP, Ordureau A, Rad R, Erickson BK, Wuhr M, Chick J, Zhai B, Kolippakkam D et al. (2015) The BioPlex Network: A Systematic Exploration of the Human Interactome. Cell 162: 425-440

Jiang H, Khan S, Wang Y, Charron G, He B, Sebastian C, Du J, Kim R, Ge E, Mostoslavsky R, Hang HC, Hao Q, Lin H (2013) SIRT6 regulates TNF-alpha secretion through hydrolysis of long-chain fatty acyl lysine. Nature 496: 110-3

Jungmichel S, Rosenthal F, Altmeyer M, Lukas J, Hottiger MO, Nielsen ML (2013) Proteomewide identification of poly(ADP-Ribosyl)ation targets in different genotoxic stress responses. Mol Cell 52: 272-85

Kaidi A, Weinert BT, Choudhary C, Jackson SP (2010) Human SIRT6 promotes DNA end resection through CtIP deacetylation. Science 329: 1348-53

Kanfi Y, Naiman S, Amir G, Peshti V, Zinman G, Nahum L, Bar-Joseph Z, Cohen HY (2012) The sirtuin SIRT6 regulates lifespan in male mice. Nature 483: 218-21

Kawahara TL, Michishita E, Adler AS, Damian M, Berber E, Lin M, McCord RA, Ongaigui KC, Boxer LD, Chang HY, Chua KF (2009) SIRT6 links histone H3 lysine 9 deacetylation to NFkappaB-dependent gene expression and organismal life span. Cell 136: 62-74

Lattanzi G, Ortolani M, Columbaro M, Prencipe S, Mattioli E, Lanzarini C, Maraldi NM, Cenni V, Garagnani P, Salvioli S, Storci G, Bonafe M, Capanni C, Franceschi C (2014) Lamins are rapamycin targets that impact human longevity: a study in centenarians. J Cell Sci 127: 147-57 Leslie Pedrioli DM, Leutert M, Bilan V, Nowak K, Gunasekera K, Ferrari E, Imhof R, Malmstrom L, Hottiger MO (2018) Comprehensive ADP-ribosylome analysis identifies tyrosine as an ADP-ribose acceptor site. EMBO Rep 19

Li J, Bonkowski MS, Moniot S, Zhang D, Hubbard BP, Ling AJ, Rajman LA, Qin B, Lou Z, Gorbunova V, Aravind L, Steegborn C, Sinclair DA (2017) A conserved NAD(+) binding pocket that regulates protein-protein interactions during aging. Science 355: 1312-1317

Li Y, Qin J, Wei X, Liang G, Shi L, Jiang M, Xia T, Liang X, He M, Zhang Z (2016) Association of SIRT6 Gene Polymorphisms with Human Longevity. Iran J Public Health 45: 1420-1426

Mao Z, Bozzella M, Seluanov A, Gorbunova V (2008) Comparison of nonhomologous end joining and homologous recombination in human cells. DNA Repair (Amst) 7: 1765-71 
Mao Z, Hine C, Tian X, Van Meter M, Au M, Vaidya A, Seluanov A, Gorbunova V (2011) SIRT6 promotes DNA repair under stress by activating PARP1. Science 332: 1443-6 Martello R, Leutert M, Jungmichel S, Bilan V, Larsen SC, Young C, Hottiger MO, Nielsen ML (2016) Proteome-wide identification of the endogenous ADP-ribosylome of mammalian cells and tissue. Nat Commun 7: 12917

Michishita E, McCord RA, Berber E, Kioi M, Padilla-Nash H, Damian M, Cheung P, Kusumoto R, Kawahara TL, Barrett JC, Chang HY, Bohr VA, Ried T, Gozani O, Chua KF (2008) SIRT6 is a histone H3 lysine 9 deacetylase that modulates telomeric chromatin. Nature 452: 492-6

Min L, Ji Y, Bakiri L, Qiu Z, Cen J, Chen X, Chen L, Scheuch H, Zheng H, Qin L, Zatloukal K, Hui L, Wagner EF (2012) Liver cancer initiation is controlled by AP-1 through SIRT6dependent inhibition of survivin. Nat Cell Biol 14: 1203-11

Montecucco A, Biamonti G (2013) Pre-mRNA processing factors meet the DNA damage response. Front Genet 4: 102

Mostoslavsky R, Chua KF, Lombard DB, Pang WW, Fischer MR, Gellon L, Liu P, Mostoslavsky G, Franco S, Murphy MM, Mills KD, Patel P, Hsu JT, Hong AL, Ford E, Cheng HL, Kennedy C, Nunez N, Bronson R, Frendewey D et al. (2006) Genomic instability and aginglike phenotype in the absence of mammalian SIRT6. Cell 124: 315-29

Naro C, Bielli P, Pagliarini V, Sette C (2015) The interplay between DNA damage response and RNA processing: the unexpected role of splicing factors as gatekeepers of genome stability.

Front Genet 6: 142

Nelson MR, Wegmann D, Ehm MG, Kessner D, St Jean P, Verzilli C, Shen J, Tang Z, Bacanu SA, Fraser D, Warren L, Aponte J, Zawistowski M, Liu X, Zhang H, Zhang Y, Li J, Li Y, Li L, Woollard P et al. (2012) An abundance of rare functional variants in 202 drug target genes sequenced in 14,002 people. Science 337: 100-4

Oughtred R, Stark C, Breitkreutz BJ, Rust J, Boucher L, Chang C, Kolas N, O'Donnell L, Leung G, McAdam R, Zhang F, Dolma S, Willems A, Coulombe-Huntington J, Chatr-Aryamontri A, Dolinski K, Tyers M (2019) The BioGRID interaction database: 2019 update. Nucleic Acids Res 47: D529-D541

Pan CP, Muino PL, Barkley MD, Callis PR (2011) Correlation of tryptophan fluorescence spectral shifts and lifetimes arising directly from heterogeneous environment. J Phys Chem B 115: 3245-53

Patil A, Nakamura H (2005) HINT: a database of annotated protein-protein interactions and their homologs. Biophysics (Nagoya-shi) 1: 21-24

Peric-Hupkes D, Meuleman W, Pagie L, Bruggeman SW, Solovei I, Brugman W, Graf S, Flicek P, Kerkhoven RM, van Lohuizen M, Reinders M, Wessels L, van Steensel B (2010) Molecular maps of the reorganization of genome-nuclear lamina interactions during differentiation. $\mathrm{Mol}$ Cell 38: 603-13

Rahnasto-Rilla M, Tyni J, Huovinen M, Jarho E, Kulikowicz T, Ravichandran S, V AB, Ferrucci L, Lahtela-Kakkonen M, Moaddel R (2018) Natural polyphenols as sirtuin 6 modulators. Sci Rep 8: 4163

Rajman L, Chwalek K, Sinclair DA (2018) Therapeutic Potential of NAD-Boosting Molecules: The In Vivo Evidence. Cell Metab 27: 529-547

Rezazadeh S, Yang D, Biashad SA, Firsanov D, Takasugi M, Gilbert M, Tombline G, Bhanu NV, Garcia BA, Seluanov A, Gorbunova V (2020) SIRT6 mono-ADP ribosylates KDM2A to locally increase H3K36me2 at DNA damage sites to inhibit transcription and promote repair. Aging (Albany NY) 12: 11165-11184 
Rezazadeh S, Yang D, Tombline G, Simon M, Regan SP, Seluanov A, Gorbunova V (2019) SIRT6 promotes transcription of a subset of NRF2 targets by mono-ADP-ribosylating BAF170. Nucleic Acids Res 47: 7914-7928

Roichman A, Elhanati S, Aon MA, Abramovich I, Di Francesco A, Shahar Y, Avivi MY, Shurgi M, Rubinstein A, Wiesner Y, Shuchami A, Petrover Z, Lebenthal-Loinger I, Yaron O, Lyashkov A, Ubaida-Mohien C, Kanfi Y, Lerrer B, Fernandez-Marcos PJ, Serrano M et al. (2021) Restoration of energy homeostasis by SIRT6 extends healthy lifespan. Nature communications 12: 3208

Roichman A, Kanfi Y, Glazz R, Naiman S, Amit U, Landa N, Tinman S, Stein I, Pikarsky E, Leor J, Cohen HY (2017) SIRT6 Overexpression Improves Various Aspects of Mouse Healthspan. J Gerontol A Biol Sci Med Sci 72: 603-615

Ryu S, Han J, Norden-Krichmar TM, Schork NJ, Suh Y (2018) Effective discovery of rare variants by pooled target capture sequencing: A comparative analysis with individually indexed target capture sequencing. Mutat Res 809: 24-31

Schaaf TM, Peterson KC, Grant BD, Bawaskar P, Yuen S, Li J, Muretta JM, Gillispie GD, Thomas DD (2017) High-Throughput Spectral and Lifetime-Based FRET Screening in Living Cells to Identify Small-Molecule Effectors of SERCA. SLAS Discov 22: 262-273

Schuster S, Roessler C, Meleshin M, Zimmermann P, Simic Z, Kambach C, Schiene-Fischer C, Steegborn C, Hottiger MO, Schutkowski M (2016) A continuous sirtuin activity assay without any coupling to enzymatic or chemical reactions. Sci Rep 6: 22643

Sebastian C, Zwaans BM, Silberman DM, Gymrek M, Goren A, Zhong L, Ram O, Truelove J, Guimaraes AR, Toiber D, Cosentino C, Greenson JK, MacDonald AI, McGlynn L, Maxwell F, Edwards J, Giacosa S, Guccione E, Weissleder R, Bernstein BE et al. (2012) The histone deacetylase SIRT6 is a tumor suppressor that controls cancer metabolism. Cell 151: 1185-99 Seluanov A, Mao Z, Gorbunova V (2010) Analysis of DNA double-strand break (DSB) repair in mammalian cells. $J$ Vis Exp

Shechter D, Dormann HL, Allis CD, Hake SB (2007) Extraction, purification and analysis of histones. Nat Protoc 2: 1445-57

Sidoli S, Bhanu NV, Karch KR, Wang X, Garcia BA (2016) Complete Workflow for Analysis of Histone Post-translational Modifications Using Bottom-up Mass Spectrometry: From Histone Extraction to Data Analysis. Journal of visualized experiments : JoVE Sidoli S, Kori Y, Lopes M, Yuan ZF, Kim HJ, Kulej K, Janssen KA, Agosto LM, Cunha J, Andrews AJ, Garcia BA (2019) One minute analysis of 200 histone posttranslational modifications by direct injection mass spectrometry. Genome Res 29: 978-987

Sidoli S, Lin S, Xiong L, Bhanu NV, Karch KR, Johansen E, Hunter C, Mollah S, Garcia BA (2015) Sequential Window Acquisition of all Theoretical Mass Spectra (SWATH) Analysis for Characterization and Quantification of Histone Post-translational Modifications. Mol Cell Proteomics 14: 2420-8

Simon M, Van Meter M, Ablaeva J, Ke Z, Gonzalez RS, Taguchi T, De Cecco M, Leonova KI, Kogan V, Helfand SL, Neretti N, Roichman A, Cohen HY, Meer MV, Gladyshev VN, Antoch MP, Gudkov AV, Sedivy JM, Seluanov A, Gorbunova V (2019) LINE1 Derepression in Aged Wild-Type and SIRT6-Deficient Mice Drives Inflammation. Cell Metab 29: 871-885 e5 TenNapel MJ, Lynch CF, Burns TL, Wallace R, Smith BJ, Button A, Domann FE (2014) SIRT6 minor allele genotype is associated with $>5$-year decrease in lifespan in an aged cohort. PLoS One 9: e115616 
Tian X, Firsanov D, Zhang Z, Cheng Y, Luo L, Tombline G, Tan R, Simon M, Henderson S, Steffan J, Goldfarb A, Tam J, Zheng K, Cornwell A, Johnson A, Yang JN, Mao Z, Manta B, Dang W, Zhang Z et al. (2019) SIRT6 Is Responsible for More Efficient DNA Double-Strand Break Repair in Long-Lived Species. Cell 177: 622-638 e22

Van Meter M, Kashyap M, Rezazadeh S, Geneva AJ, Morello TD, Seluanov A, Gorbunova V (2014) SIRT6 represses LINE1 retrotransposons by ribosylating KAP1 but this repression fails with stress and age. Nat Commun 5: 5011

Van Meter M, Mao Z, Gorbunova V, Seluanov A (2011) SIRT6 overexpression induces massive apoptosis in cancer cells but not in normal cells. Cell Cycle 10: 3153-8

Van Meter M, Simon M, Tombline G, May A, Morello TD, Hubbard BP, Bredbenner K, Park R, Sinclair DA, Bohr VA, Gorbunova V, Seluanov A (2016) JNK Phosphorylates SIRT6 to Stimulate DNA Double-Strand Break Repair in Response to Oxidative Stress by Recruiting PARP1 to DNA Breaks. Cell Rep 16: 2641-50

Vivelo CA, Wat R, Agrawal C, Tee HY, Leung AK (2017) ADPriboDB: The database of ADPribosylated proteins. Nucleic Acids Res 45: D204-D209

Vohhodina J, Barros EM, Savage AL, Liberante FG, Manti L, Bankhead P, Cosgrove N, Madden AF, Harkin DP, Savage KI (2017) The RNA processing factors THRAP3 and BCLAF1 promote the DNA damage response through selective mRNA splicing and nuclear export. Nucleic Acids Res 45: 12816-12833

Wisniewski JR (2017) Label-Free and Standard-Free Absolute Quantitative Proteomics Using the "Total Protein" and "Proteomic Ruler" Approaches. Methods Enzymol 585: 49-60

Zhang W, Wan H, Feng G, Qu J, Wang J, Jing Y, Ren R, Liu Z, Zhang L, Chen Z, Wang S, Zhao Y, Wang Z, Yuan Y, Zhou Q, Li W, Liu GH, Hu B (2018) SIRT6 deficiency results in developmental retardation in cynomolgus monkeys. Nature 560: 661-665

Zullo JM, Demarco IA, Pique-Regi R, Gaffney DJ, Epstein CB, Spooner CJ, Luperchio TR, Bernstein BE, Pritchard JK, Reddy KL, Singh H (2012) DNA sequence-dependent compartmentalization and silencing of chromatin at the nuclear lamina. Cell 149: 1474-87 


\section{FIGURE LEGENDS}

Figure 1: CentSIRT6 missense variant identified in AJ centenarians demonstrates lower deacetylation activity

A, B Histograms of normalized allele counts for SNPs in individuals 75+ years old compared to all age groups $(\mathrm{N}=125,748)$ across $(\mathbf{A})$ entire chromosome 19, and $(\mathbf{B})$ missense SNPs and indels only. Dotted vertical lines show centSIRT6.

C The structure of the SIRT6 gene. centSIRT6 contains two missense mutations in the Cterminus $\mathrm{N} 308 \mathrm{~K}$ and $\mathrm{A} 313 \mathrm{~S}$. White boxes represent UTRs, colored boxes represent protein coding regions, and blue boxes represent enzymatic domains.

D Michaelis-Menten kinetic parameters as calculated by saturation curves using differential concentrations of myristoylated peptide or $\mathrm{NAD}^{+}$. Reactions were conducted in triplicate.

E, F Deacetylase activity on $\mathrm{H} 3 \mathrm{~K} 9$ (E) and H3K18 (F) residues shows reduced activity in centSIRT6 allele. Designer histones saturated with the corresponding acetylated histone residue were incubated with purified SIRT6 and $1 \mathrm{mM} \mathrm{NAD}^{+}$for $1 \mathrm{~h}$ prior to resolution by SDS-PAGE gel and staining with acetyl-specific histone antibodies.

All reactions were conducted with an $n=3$; error bars show s.d. Statistics were calculated using Students $t$-test, two tailed. Asterisk indicate $p<0.05$.

\section{Figure 2: CentSIRT6 possesses reduced deacetylase activity}

A, B Deacetylation kinetics of SIRT6 variants. Designer histones were incubated with purified SIRT6 and $5 \mathrm{mM} \mathrm{NAD}{ }^{+}$, then resolved by SDS-PAGE and analyzed by immunoblotting with acetyl-specific histone antibodies. HeLa histone preps were also probed as shown in Fig EV3A.

C Quantitative mass spec of histone $\mathrm{H} 3$ peptide purified from human cells expressing different SIRT6 alleles did not reveal a difference in acetylation levels. Relative fraction represents the portion of the peptide encompassing H3K9-17 compared to the summed total of all of the peptide quantitation values for the same region. The average and standard deviation of three different preps is plotted. Acetylation of other H3 peptides is shown in Supplementary Data 1. Histone preparation is shown in Fig EV3D.

D Whole cell histone H3 acetylation levels in cumate-inducible SIRT6 human fibroblasts, assessed by Western blot. $\mathrm{Cu}$, cumate; $\mathrm{PQ}$, paraquat. Cumate dosage required for equivalent 
SIRT6 protein abundance was determined by Western blot, and administered accordingly to respective cell lines (Fig EV3B, EV3C).

\section{Figure 3: CentSIRT6 demonstrates enhanced mADPr activity}

A Self-ribosylation of SIRT6 using biotin-labeled NAD ${ }^{+}$. Recombinant SIRT6 was incubated with $\mathrm{NAD}^{+}$conjugated with a biotin residue and then run on an SDS-PAGE. Each allele was assessed relative to its $0 \mathrm{hr}$ time point and normalized to SIRT6 total protein loading controls.

B Self-ribosylation of SIRT6 with titration of NAD ${ }^{+}$. mADPr-specific antibody(Bonfiglio et al., 2020) was used to detect ribosylated wild type SIRT6 and centSIRT6 proteins. Plot was fit the Michaelis-Menten equation with Kaleidagraph software. $K_{m}$ NAD was $142 \pm 29$ for centSIRT6 and $106 \pm 45$ for wild type SIRT6 and maximal signal was $\sim 2 \mathrm{x}$ greater for centSIRT6 compared to the wild type SIRT6.

C Activation of PARP1 by SIRT6 variants. SIRT6 protein was incubated with human PARP1 protein and then analyzed by immunoblotting with poly-ADPr antibody. Poly-ADPr activity of PARP1 results in a wide range of product size. Activity was assessed by quantifying poly-ADPr signal in whole lanes for each sample.

All experiments were repeated at least three times; error bars show s.d. Significance was determined by Student's $t$-test, two tailed. Asterisk indicate $p<0.05$. Black asterisks indicate significance over HPRT control. Red asterisks indicated significance over wild type SIRT6.

\section{Figure 4: CentSIRT6 enhances LINE1 retrotransposon suppression and DNA repair}

A qRT-PCR analysis of LINE1 expression in cumate-inducible SIRT6 fibroblasts. Primers assessed both 5' (ORF1) and 3' (ORF2) LINE1 sequences from the L1MdA1 family of active LINE1 retrotransposons. Assessment of both regions was conducted to mitigate contributions from partial insertion sequences in coding genes.

B, C Stimulation of NHEJ and HR by SIRT6 variants. Reporter cell lines were co-transfected with SIRT6-expressing plasmid, I-Sce1 plasmid, and DsRed transfection control. After $72 \mathrm{hr}$ recovery, reactivation of the GFP reporter was measured by flow cytometry. Stimulation of NHEJ or HR was calculated as radio of $\mathrm{GFP}^{+} / \mathrm{DsRed}^{+}$positive cells. Representative FACS traces are shown in Fig EV5A. 
D Basal $\gamma \mathrm{H} 2 \mathrm{AX}$ foci in cumate-inducible SIRT6 fibroblasts. Foci were scored in at least 80 cells per condition. Representative images of the foci are shown in Fig EV4B.

E DNA repair kinetics in cumate-inducible SIRT6 fibroblasts. Cells were grown on slides and irradiated with 2 Gy gamma radiation, followed by immunostaining for $\gamma \mathrm{H} 2 \mathrm{AX}$. Irradiation was conducted when the cells were at $75 \%$ confluency on slides. Cells were fixed and foci scored at $\mathrm{t}=0.5 \mathrm{hr}, 2 \mathrm{hr}, 4 \mathrm{hr}, 6 \mathrm{hr}$, and $24 \mathrm{hr}$ post-irradiation. Foci were scored in at least 80 cells per genotype per timepoint. Representative images of the foci are shown in Fig EV5C. Asterisk indicates significant difference from the wild type SIRT6 $(p<0.05)$. Color of the asterisk corresponds to the SIRT6 allele.

F, G Oxidative stress resistance. Cumate-inducible SIRT6 fibroblasts were induced for SIRT6 expression and exposed to paraquat for 24 hours. Resistance was determined by apoptosis staining 48 hours after exposure. Representative FACS traces are shown Fig EV5D.

All experiments were repeated at least three times. Error bars represent s.d. Significance was determined by Student's $t$-test, two tailed, unless otherwise stated. Asterisk indicate $p<0.05$. Except in $\mathbf{E}$ and $\mathbf{G}$, red asterisk indicates significant difference from control, and black asterisk indicates significant difference from the wild type SIRT6.

\section{Figure 5: CentSIRT6 induces increase cell death in cancer cells}

A Number of adherent cells after transfection with SIRT6 variants. Cells were transfected with SIRT6 plasmids encoding different SIRT6 alleles and cell numbers were counted after 72 hours. HCA2 are normal human foreskin fibroblasts. Asterisk indicates significant difference from the wild type SIRT6 $(p<0.05)$. Color of the asterisk corresponds to the SIRT6 allele.

B, C Apoptosis staining of cancer cell lines 48 hours after transfection. Cells were stained with Annexin V/PI and analyzed by flow cytometry. Significance was determined by two-way ANOVA.

All experiments were repeated at least three times. Error bars represent s.d. Significance was determined by Student's $t$-test, two tailed, unless otherwise stated. Asterisk indicate $p<0.05$. Red asterisk indicates significant difference from control, and black asterisk indicates significant difference from the wild type SIRT6.

\section{Figure 6: CentSIRT6 allele shows enhanced interaction with LMNA}


A Proteins showing stronger interaction with centSIRT6 compared to the wild type SIRT6. Proteins were prepared from cumate-induced SIRT6 cell lines and immuno-precipitated with SIRT6 antibody; rabbit pre-immune serum was used as a control. Prior to analysis by mass spectrometry, samples were labeled with tandem-mass tags.

B IP experiments on lysates from cumate-induced fibroblasts expressing wild type or centSIRT6 alleles with antibodies to SIRT6, LMNA, and mADPr. SIRT6 expression was induced 48 hours prior to IP. The IP experiments were repeated three times. One representative set of IPs is shown.

C CentSIRT6 shows stronger interaction with LMNA compared to the wild type SIRT6. Quantification of the IP experiment shown in (B). SIRT6 IP followed by Western blot with antibodies to LMNA.

D LMNA shows enhanced interaction with centSIRT6 compared to the wild type. Quantification of the IP experiment shown in (B). LMNA IP from cumate-inducible SIRT6 fibroblasts followed by Western blot with antibodies to SIRT6.

E centSIRT6 shows enhanced mADPr. Quantification of the IP experiment shown in (B). SIRT6 IP from cumate-inducible SIRT6 fibroblasts followed by Western blot with antibody to mADPr residues(Bonfiglio et al., 2020)

F LMNA shows enhanced mADPr signal in cells expressing centSIRT6. Quantification of the IP experiment shown in (B). IP with mADPr antibody(Bonfiglio et al., 2020) using extract from cumate-induced SIRT6 fibroblasts, followed by Western blot with antibodies to LMNA.

G SIRT6 and LMNA are colored red and featured as central points in two opposing nodes of interactions. A third node (upper middle) shows interaction partners that are shared by SIRT6 and LMNA. Proteins whose interactions are enhanced by the centSIRT6 allele are colored yellow. Proteins that interacted equally with wild type and centSIRT6 alleles are uncolored. H1.5 is a special case and colored orange because it showed increased interaction with the centSIRT6 and decreased interaction with LMNA in the presence of the centSIRT6 allele. Proteins known to be ribosylated in previous reports are shown as hexagons.

Error bars represent s.d. Significance was determined by Student's $t$-test, two tailed. Asterisk indicate $p<0.05$

\section{Figure 7: Altered molecular functions of centSIRT6}


CentSIRT6 allele shows reduced deacetylation activity and enhanced mADPr activity. This results in enhanced DNA repair, improved LINE1 suppression and cancer cell killing. centSIRT6 shows stronger interaction with LMNA and enhances LMNA interactions with its partners. 


\section{TABLES}

Table I. List of all SIRT6 variants identified by capture sequencing

\begin{tabular}{|c|c|c|c|c|c|c|c|c|c|c|c|c|c|c|c|}
\hline \multirow[b]{2}{*}{ SNP ID } & \multirow[b]{2}{*}{ Alt } & \multirow[b]{2}{*}{ Ref } & \multirow[b]{2}{*}{$\begin{array}{l}\text { Variant } \\
\text { Type }\end{array}$} & \multirow[b]{2}{*}{$\begin{array}{l}\text { AA } \\
\text { change }\end{array}$} & \multicolumn{3}{|c|}{$\begin{array}{l}\text { Current Study } \\
\text { Centenarians }\end{array}$} & \multicolumn{4}{|c|}{$\begin{array}{c}\text { Current Study } \\
\text { Controls }\end{array}$} & \multicolumn{4}{|c|}{$\begin{array}{l}\text { GnomAD } \\
\text { Controls }\end{array}$} \\
\hline & & & & & $\begin{array}{c}\text { Alt } \\
\text { Count }\end{array}$ & $\begin{array}{c}\text { Ref } \\
\text { Count }\end{array}$ & MAF & $\begin{array}{c}\text { Alt } \\
\text { Count }\end{array}$ & $\begin{array}{c}\text { Ref } \\
\text { Count }\end{array}$ & MAF & $\mathbf{P}$ & $\begin{array}{c}\text { Alt } \\
\text { Count }\end{array}$ & $\begin{array}{c}\text { Ref } \\
\text { Count }\end{array}$ & MAF & $\mathbf{P}$ \\
\hline rs350845 & $G$ & $A$ & intron & - & 749 & 151 & 0.17 & 962 & 138 & 0.126 & 0.009 & 8783 & 1367 & 0.135 & 0.007 \\
\hline rs11554579 & $\mathrm{C}$ & $\mathrm{T}$ & synonym & R76R & 13 & 887 & 0.014 & 10 & 1090 & 0.009 & 0.296 & 91 & 9785 & 0.009 & 0.15 \\
\hline rs183444295 & A & C & missense & A313S & \multirow{2}{*}{9} & \multirow{2}{*}{891} & \multirow{2}{*}{0.010} & \multirow{2}{*}{6} & \multirow{2}{*}{1094} & \multirow{2}{*}{0.006} & \multirow{2}{*}{0.3} & 25 & 4281 & 0.006 & 0.267 \\
\hline rs201141490 & C & $\mathbf{G}$ & missense & N308K & & & & & & & & 28 & 4826 & 0.006 & 0.268 \\
\hline rs748302927 & $\mathrm{T}$ & $G$ & intron & - & 1 & 899 & 0 & 0 & 1100 & 0 & 0.45 & 5 & 9375 & $5 E-04$ & 0.423 \\
\hline rs992892719 & $G$ & $\mathrm{C}$ & missense & R291P & 24 & 876 & 0.03 & 27 & 1073 & 0.025 & 0.777 & 0 & 6726 & 0 & $<0.001$ \\
\hline rs200174862 & $\mathrm{T}$ & $G$ & intron & - & 1 & 899 & 0 & 1 & 1099 & $9 \mathrm{E}-04$ & 1 & 3 & 4777 & $6 \mathrm{E}-04$ & 0.499 \\
\hline rs200813796 & $\mathrm{T}$ & $\mathrm{C}$ & $3^{\prime}$ UTR & - & 3 & 897 & 0 & 3 & 1097 & 0.003 & 1 & 11 & 4075 & 0.003 & 0.728 \\
\hline
\end{tabular}

AJ, Ashkenazi Jewish; MAF, minor allele frequency; REF, reference allele; ALT, alternative allele; CON, controls; CENT, centenarians; P-values from Fisher exact test on allele counts. 


\section{EXPANDED VIEW FIGURES}

\section{Figure EV1. rs350845 (chr19:4174953:A:G) is a cis-eQTL for SIRT6 upregulation across multiple tissues.}

A GTEx Tissue types are shown sorted by m-value which is the posterior probability that an eQTL exists for SIRT6 in a specific tissue from a cross-tissue meta-analysis. NES = Normalized Effect Size based on single-tissue analysis; p-value is from a t-test comparing observed NES to a null within a single-tissue.

B Single tissue eQTL p-value vs. m-values.

C Violin plots showing SIRT6 expression differences across three example tissues with m-value $=1$. Reference allele is $\mathrm{G}$ and alternate allele is $\mathrm{A}$, and each panel shows the normalized expression of SIRT6 in a different tissue. Values beneath genotypes represent number of individuals.

\section{Figure EV2: Turnover rate and biochemical properties of purified SIRT6 proteins}

A Protein turn-over rate. SILAC analysis on HEK293 cells expressing SIRT6 variants.

B Coomassie staining of SIRT6 purified from Rosetta-Gami E. coli cells. Proteins were purified at the University of Rochester (Roc) as well as the Ichor Therapeutics facility in Ithaca. All in vitro experiments were performed with both protein preparations and the data was consistent between the two preps.

C Thermostability of purified SIRT6 proteins. Data represents two replicates with two technical replicates each using SIRT6 from the Roc and Ichor preps.

D FRET biosensor design. Top: RFP-SIRT6-GFP with RFP (acceptor) and GFP (donor) fused to N- and C-termini of SIRT6. Bottom: RFP-SIRT6-intra-GFP with GFP inserted internally within SIRT6 after D206.

E Representative Fluorescence lifetime (FLT) signals acquired from four different transiently transfected cell lines.

F Fluorescence lifetime $\tau$ measured from FLT signals by fitting the data to Eq. 1 (see Methods). Each of the two different SIRT6 biosensors shows a decreased fluorescence lifetime compared to the GFP-only control, indicating highly significant FRET. Compared with the biosensor with C- 
terminal GFP (pink), the intra-GFP biosensor (black) shows a greater lifetime change (more FRET, shorter distance R, more structural sensitivity). The centSIRT6 of this biosensor was also tested (red). It shows a significant increase in lifetime $\tau(1.96 \pm 0.02 \mathrm{~ns})$, compared to the wild type SIRT6 (1.75 $\pm 0.01 \mathrm{~ns})$. Error bars indicate SEM $(\mathrm{n}=3-5)$.

G The FRET efficiency E and the distance R were determined from lifetime data (Eqs. 2 and 3, Methods), revealing that the distance R, measure for the intra-GFP biosensor, was significantly greater for the centSIRT6 by $3.0 \pm 0.4 \AA$.

H Tryptophan fluorescence curves for SIRT6 variants with titrated concentrations of NAD ${ }^{+}$.

Figure EV3: HeLa histone deacetylation by recombinant SIRT6, and SIRT6 expression in cumate-inducible cell lines

A In vitro deacetylation rates of purified SIRT6 proteins with histones purified from HeLa cells.

B SIRT6 expression in cumate-inducible telomerase-immortalized HCA2 human fibroblast cell lines. SIRT6 alleles were integrated in the genome of SIRT6 knockout HCA2 cells using PiggyBac Transposon Vector System. Different dosages of cumate and resulting SIRT6 abundance were used to determine the dose needed to achieve equivalent SIRT6 expression for each cell line. Cells were normalized by count and total protein. Subsequent experiments utilizing cumate-inducible SIRT6 fibroblasts were controlled for SIRT6 abundance using these data.

For each cell line, the red box indicates the corresponding cumate dosage for equivalent expression $(\mathrm{WT}=60 \mu \mathrm{g} / \mathrm{ml}, \mathrm{N} 308 \mathrm{~K}=30 \mu \mathrm{g} / \mathrm{ml}, \mathrm{A} 313 \mathrm{~S}=30 \mu \mathrm{g} / \mathrm{ml}$, and Cent=7.5 $\mu \mathrm{g} / \mathrm{ml}$ ). These concentrations were used in experiments with these cells.

C qRT-PCR expression analysis of SIRT6 using standardized dosages of cumate (dosage corresponds to red boxes in Fig EV3B

D Coomassie stained SDS-PAGE of histone preparations for quantitative mass spectrometry

\section{Figure EV4: Quantification of SIRT6 expression and FACS gating for DNA repair assays}

A Representative images of FACS analysis for DNA DSB repair assays (Fig 4B, C).

B Representative images of basal $\gamma \mathrm{H} 2 \mathrm{AX}$ immunostaining (Fig 4D).

C Representative images of $\gamma \mathrm{H} 2 \mathrm{AX}$ immunostaining after $\gamma$-irradiation (Fig 4E).

D Representative images of FACS traces for paraquat sensitivity assay (Fig 4F, G). 


\section{Figure EV5: Analysis of CRISPR human MSC cell lines}

A, B DNA double strand repair efficiency in wild type and centSIRT6 hMSCs. DSB repair reporter constructs were integrated into hMSCs. After $72 \mathrm{hr}$ recovery, reactivation of the GFP reporter was measured by flow cytometry. Stimulation of NHEJ or HR was calculated as radio of $\mathrm{GFP}^{+} / \mathrm{DsRed}^{+}$positive cells.

C Cell viability in MMS-treated wild type and centSIRT6 hMSCs. hMSCs were treated with MMS for 48 hours and cell viability was evaluated by MTS assay. Data were normalized to the control group $(0 \mathrm{mM}) \cdot \mathrm{n}=6$.

D Immunofluorescence staining of 53BP1 in wild type and centSIRT6 hMSCs under MMS treatment. Numbers of 53BP1 foci in the nuclei of wild type and centSIRT6 hMSCs with or without MMS (0.25 mM) treatment were quantified. >600 nuclei from 10 images were scored.

E qRT-PCR analysis of SIRT6 expression in wild type and centSIRT6 hMSCs (P2). Data normalized to Actin and were presented as mean \pm SEM, NS, not significant.

F Western blot analysis of SIRT6 in wild type and centSIRT6 hMSCs. $\beta$-Actin was used as a loading control and used to normalize quantification.

Error bars represent s.d. Significance was determined by Student's $t$-test, two tailed. Asterisk indicate $p<0.05$ 
bioRxiv preprint doi: https://doi.org/10.1101/2021.12.13.472381; this version posted December 13, 2021. The copyright holder for this preprint

A

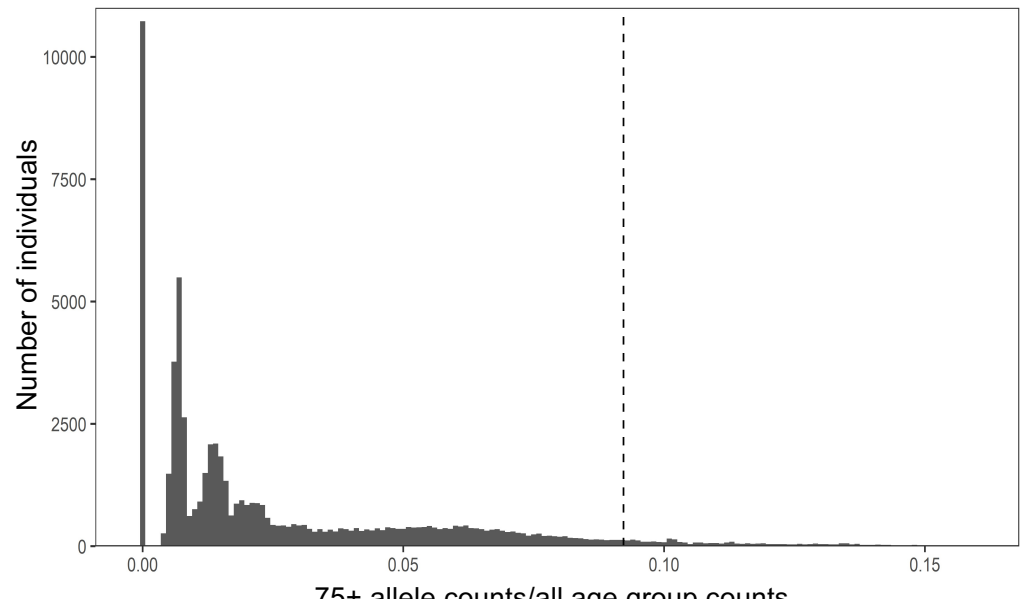

$75+$ allele counts/all age group counts

\section{C}

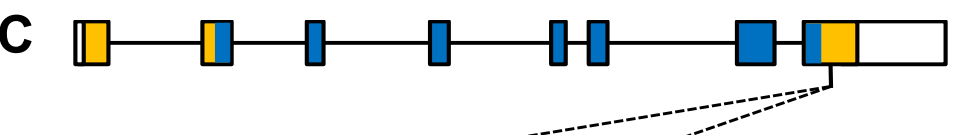

CGGATCAÄCGGCTCTATCCCCGC̈GGCCCC WT
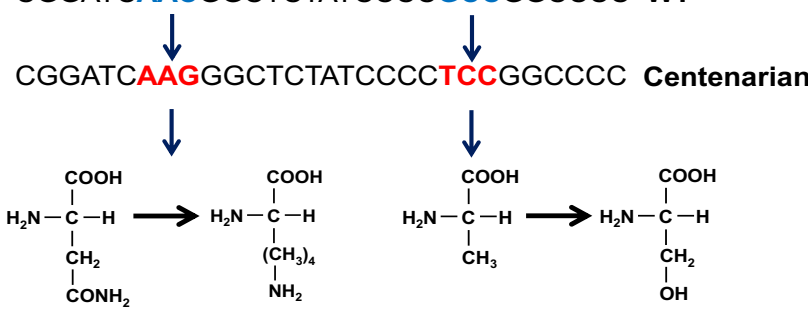

Ala to Ser (A313S)

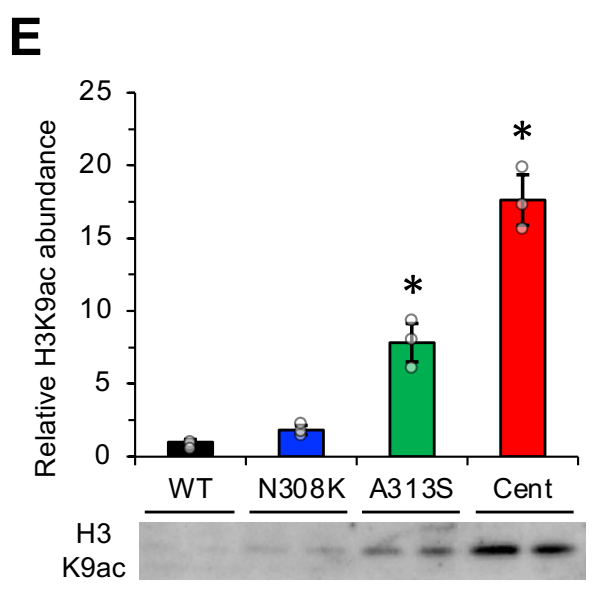

B

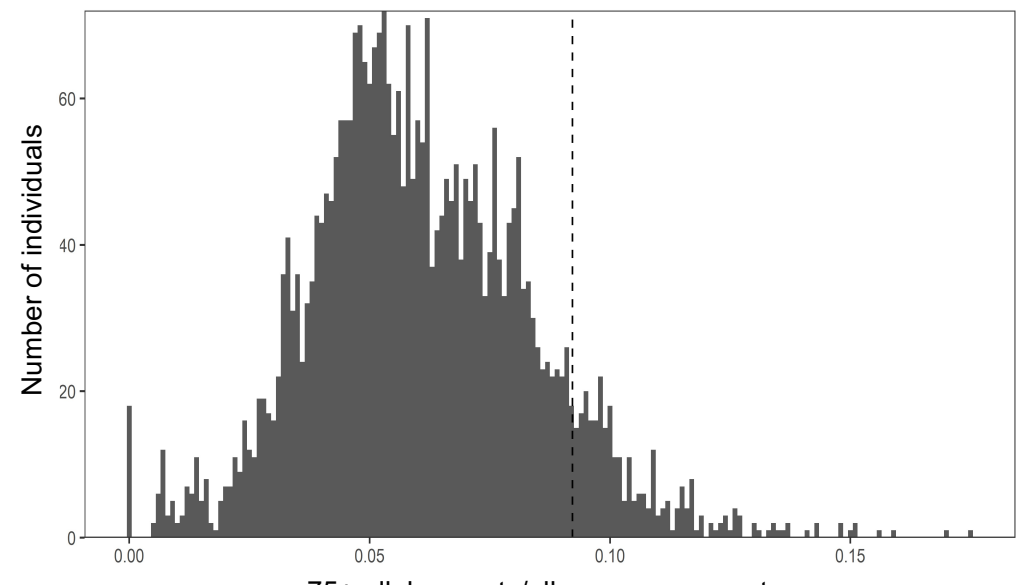

$75+$ allele counts/all age group counts

D
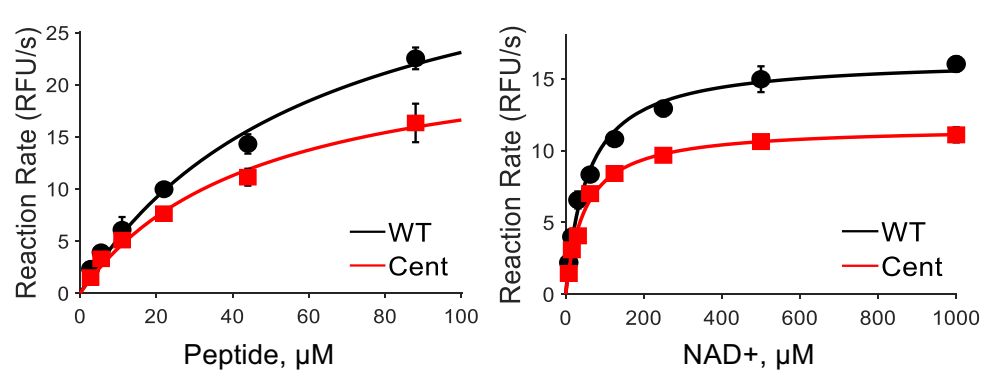

\begin{tabular}{|c|c|c|c|c|}
\hline & $\begin{array}{c}\mathrm{Km}_{\text {NAD }} \\
(\mu \mathrm{M})\end{array}$ & $\mathrm{Km}_{\text {pep }}(\mu \mathrm{M})$ & $\begin{array}{c}\text { Vmax } \\
(\mathbf{R F U} / \mathbf{s})\end{array}$ & Vmax/Km $\mathbf{K m e}$ \\
\hline WT & $55.5 \pm 5.4$ & $61.1 \pm 12.4$ & $37.2 \pm 4.1$ & 0.61 \\
\hline Cent & $48.4 \pm 3.7$ & $46 \pm 11.3$ & $24.3 \pm 2.9^{*}$ & 0.53 \\
\hline
\end{tabular}

F

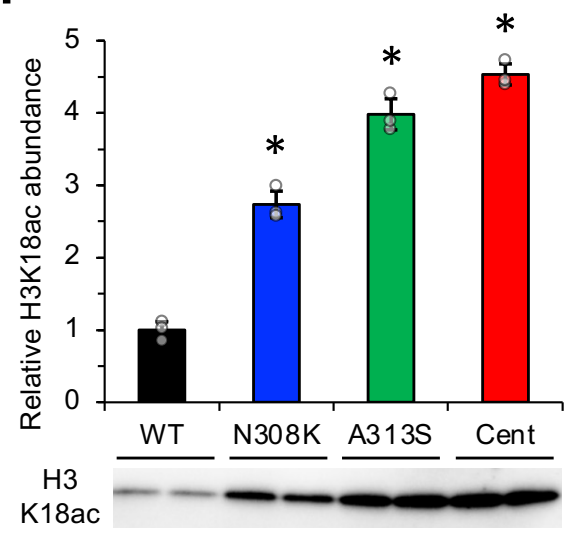


A
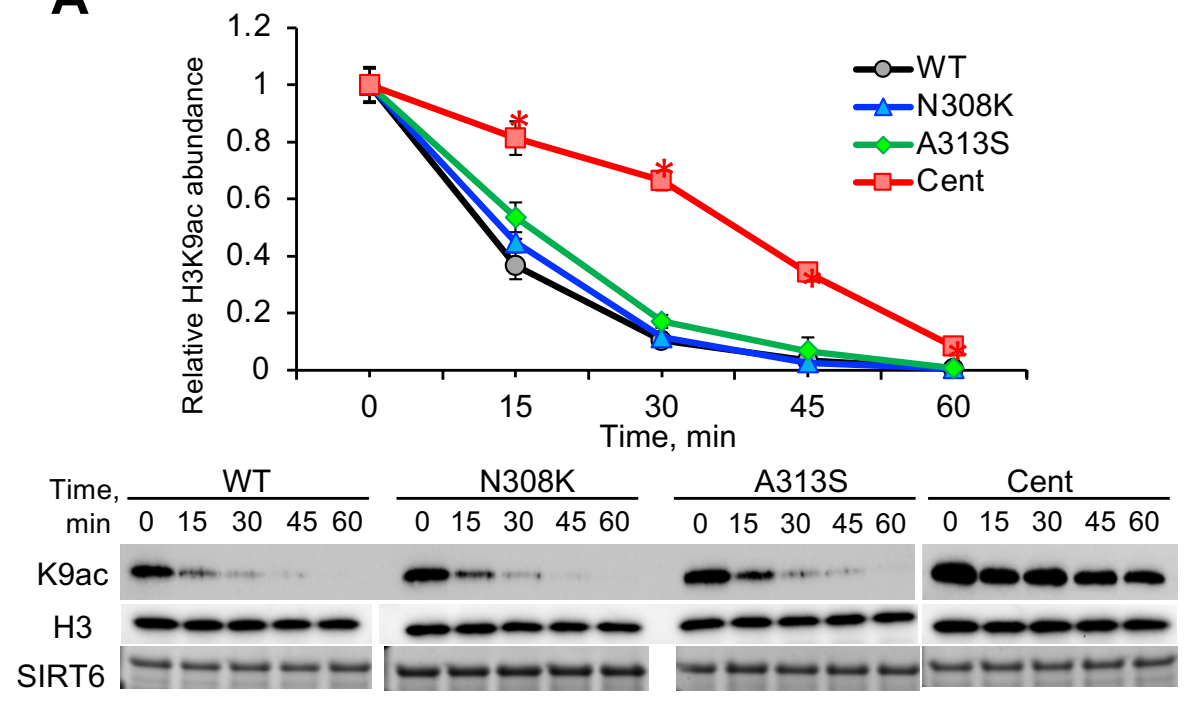

B
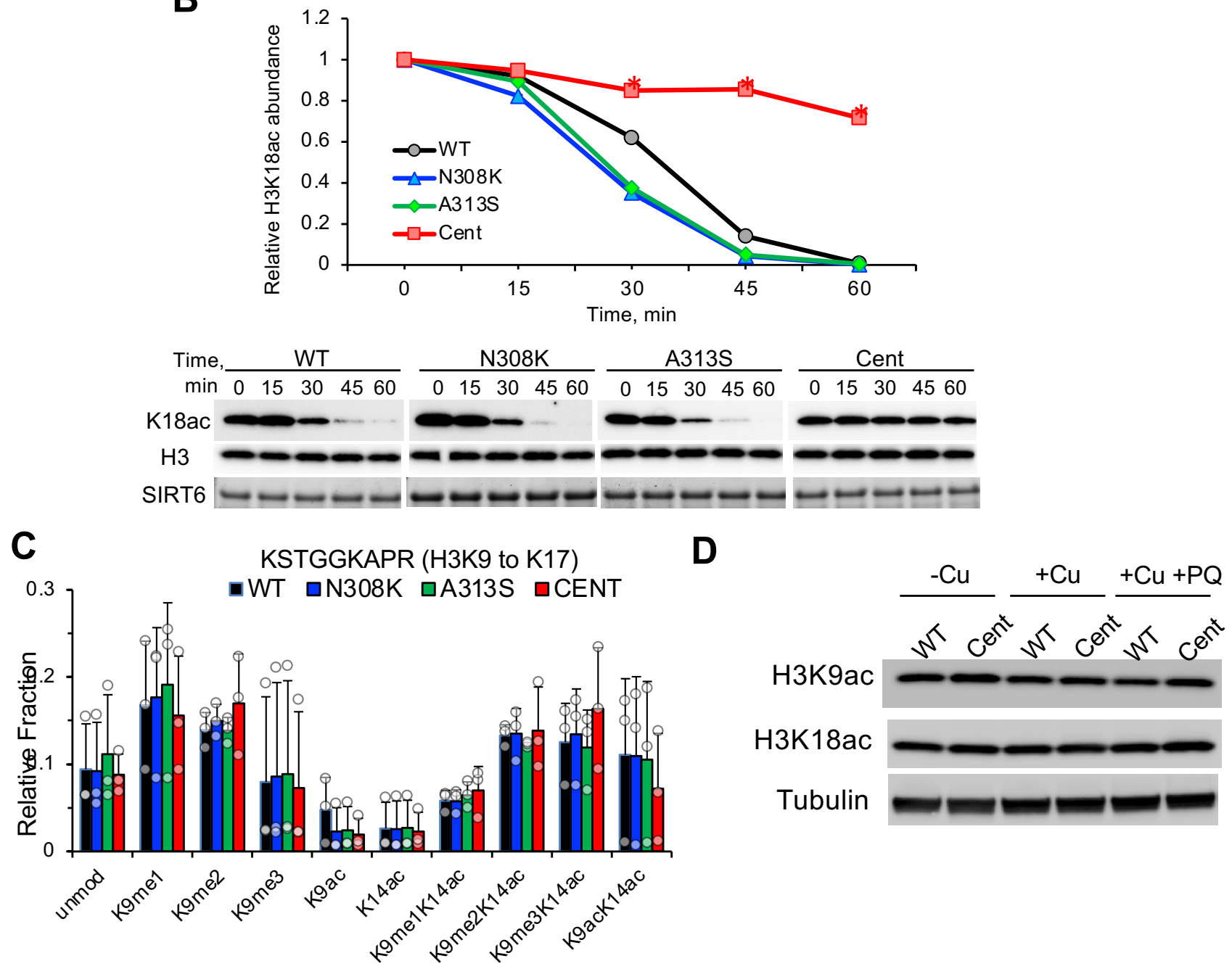
A

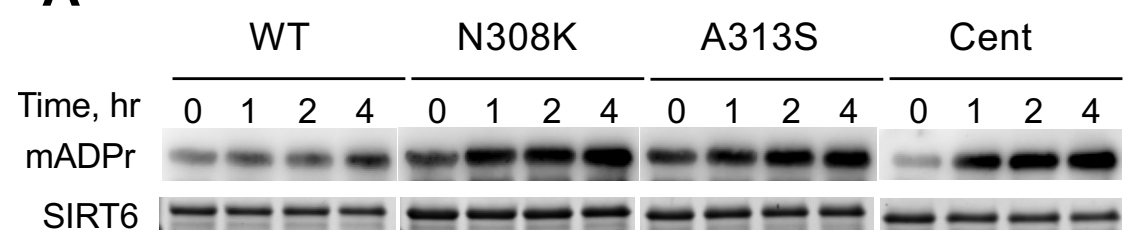

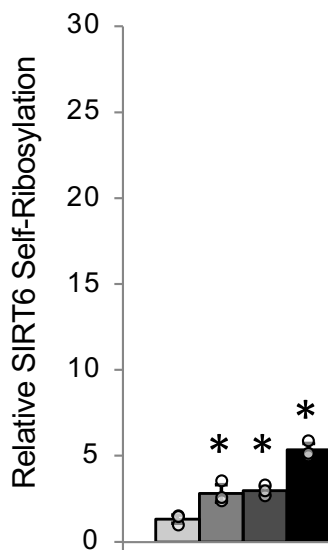

Time, hr
B $N A D^{+}, \mu \mathrm{M}$

C

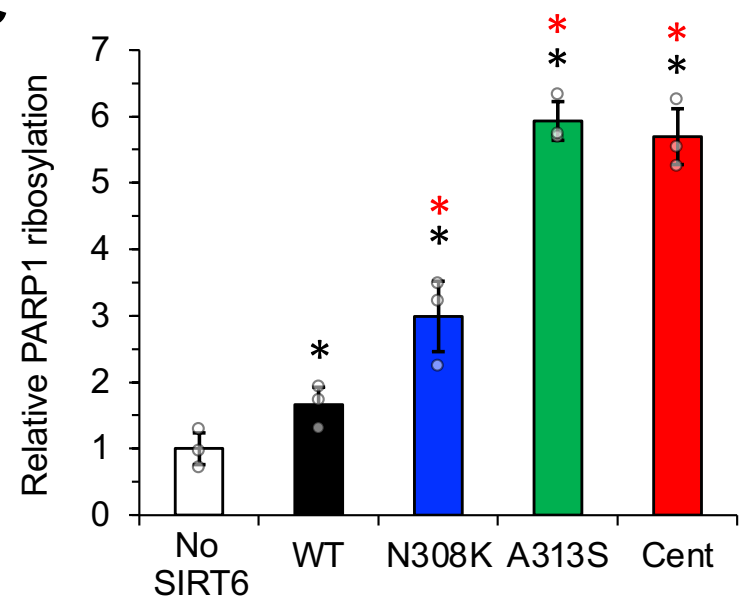

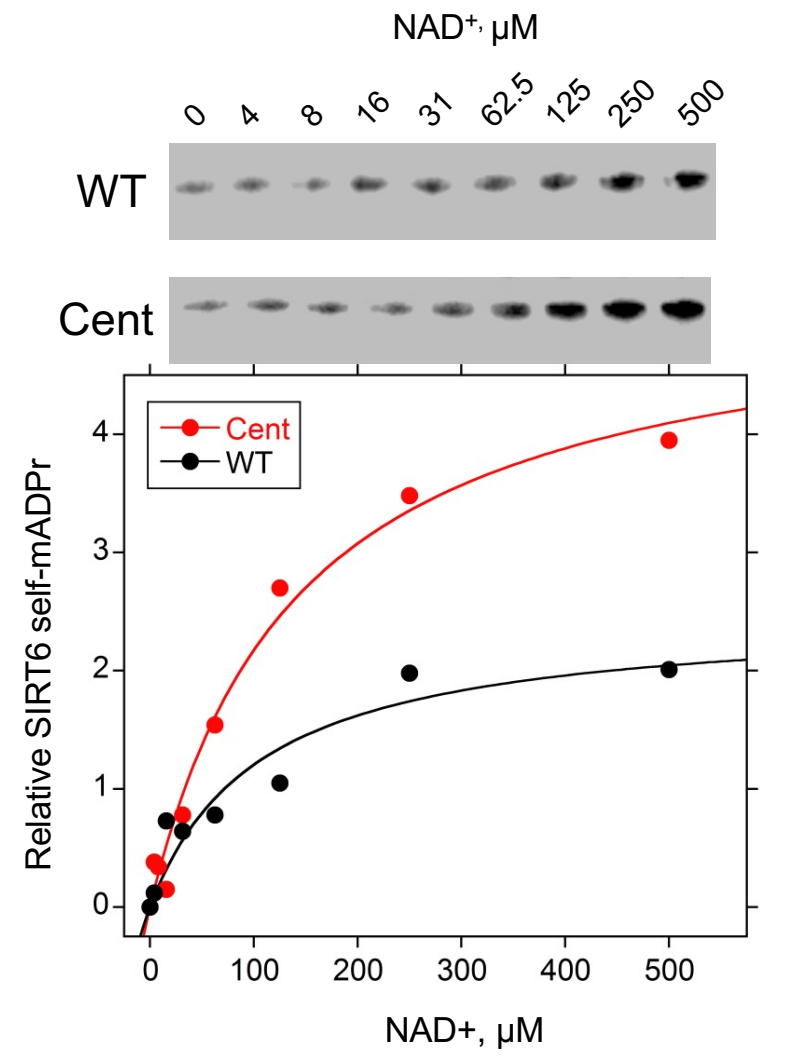

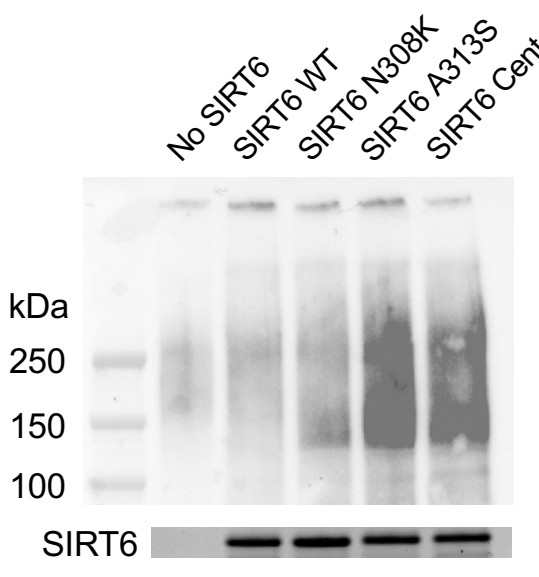



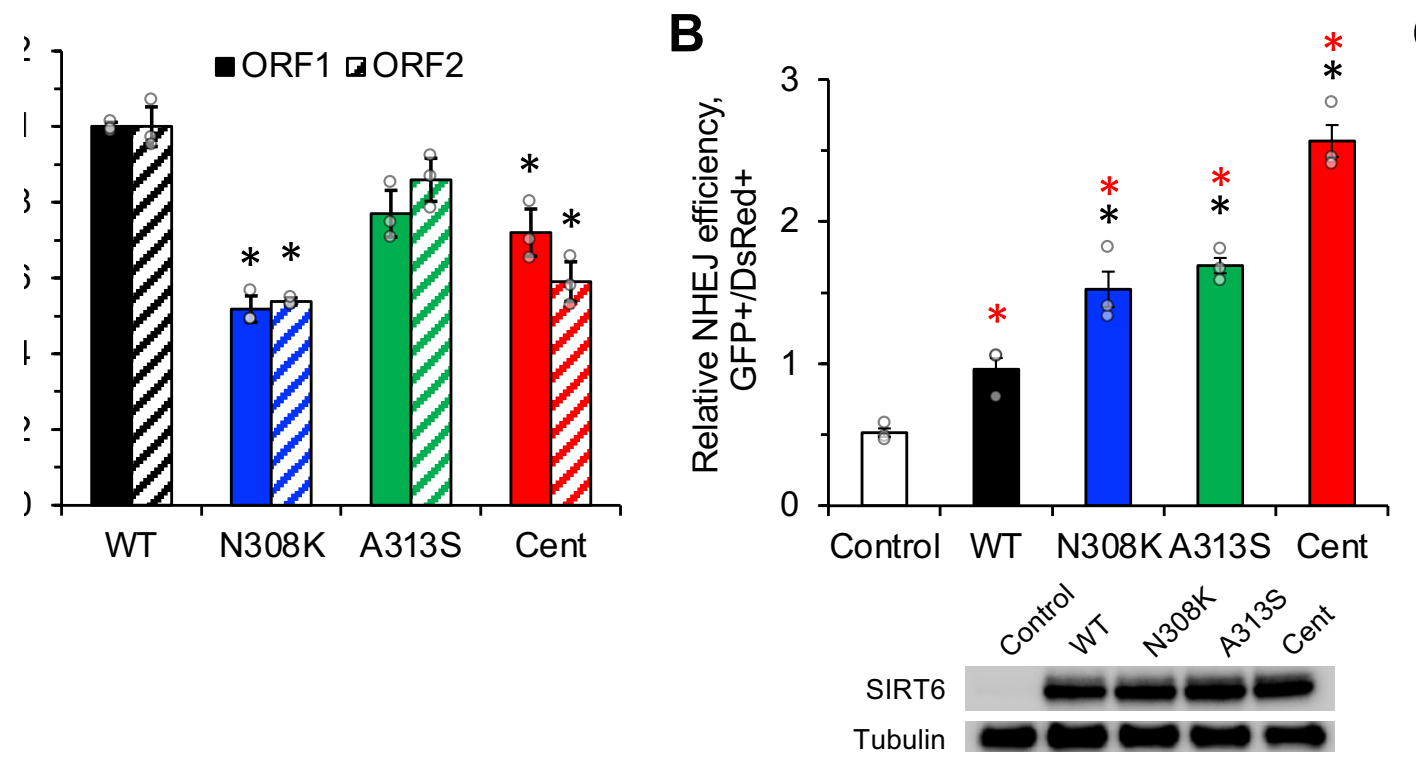

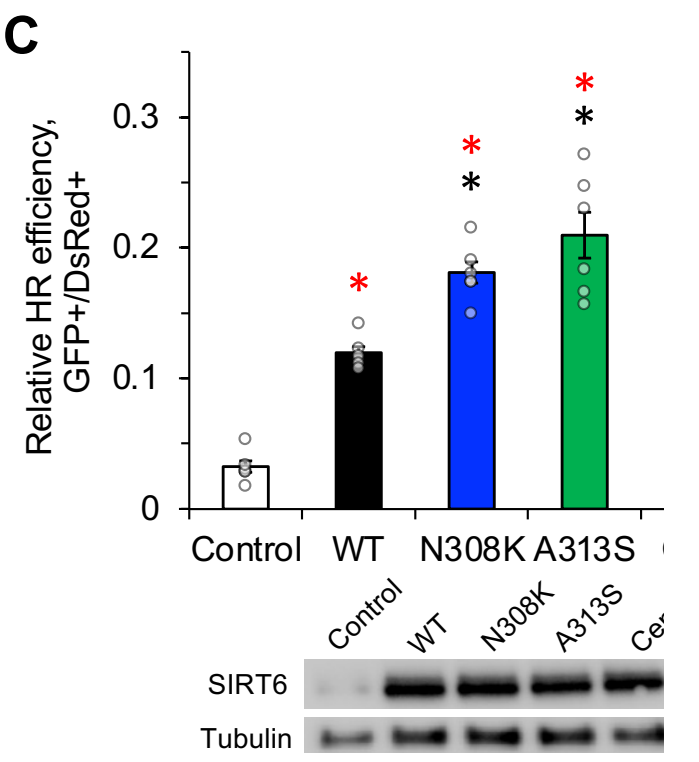

E
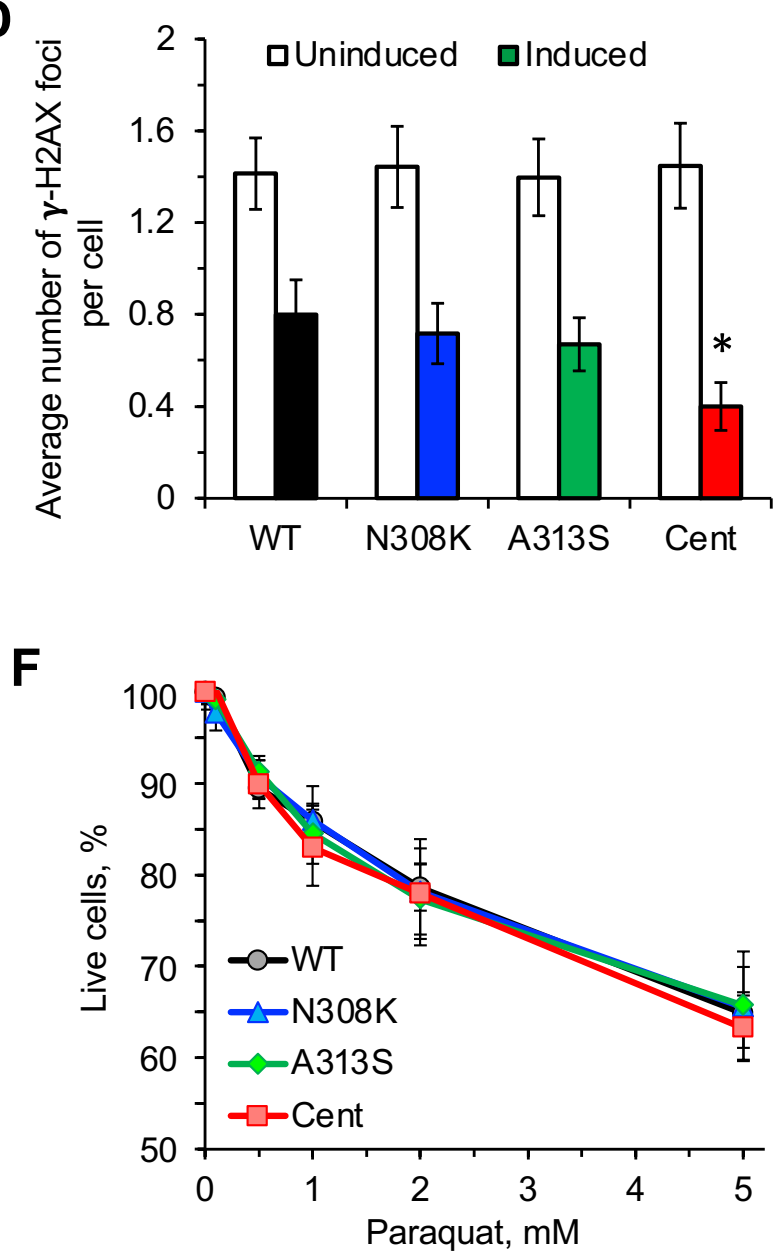
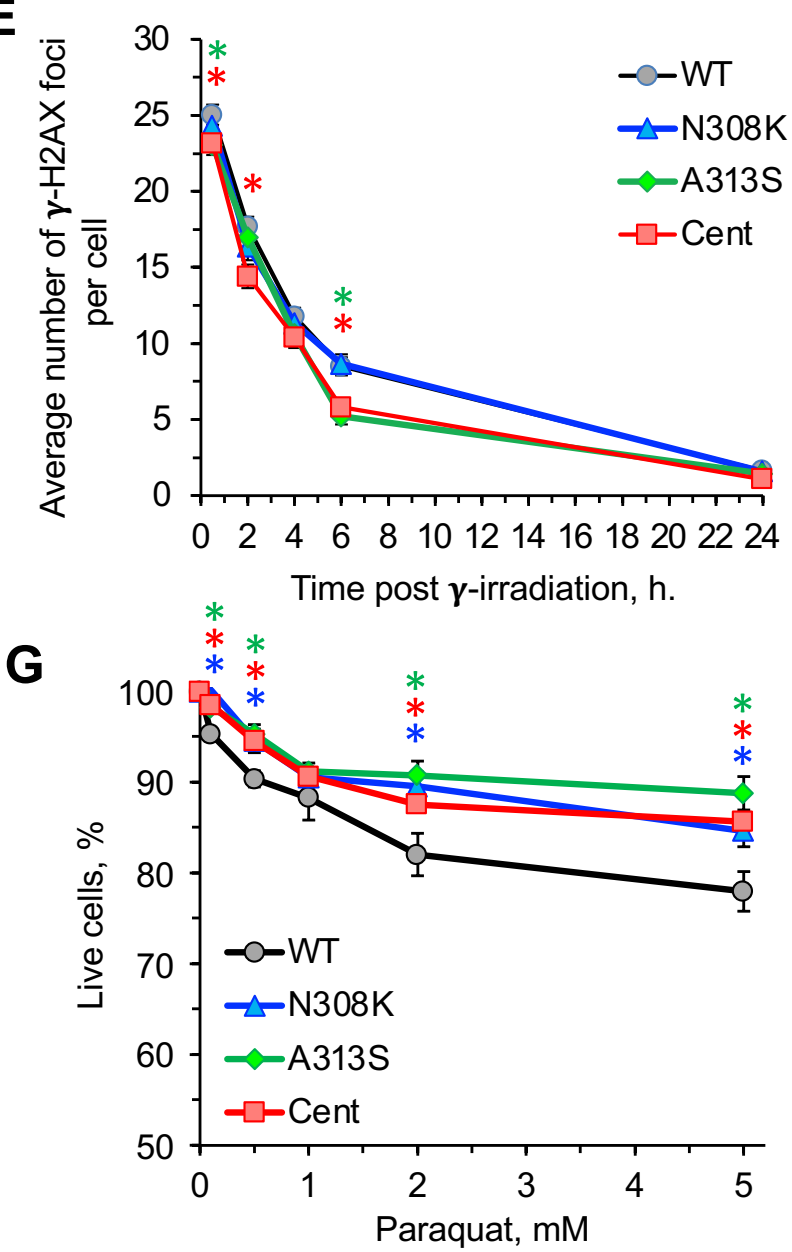

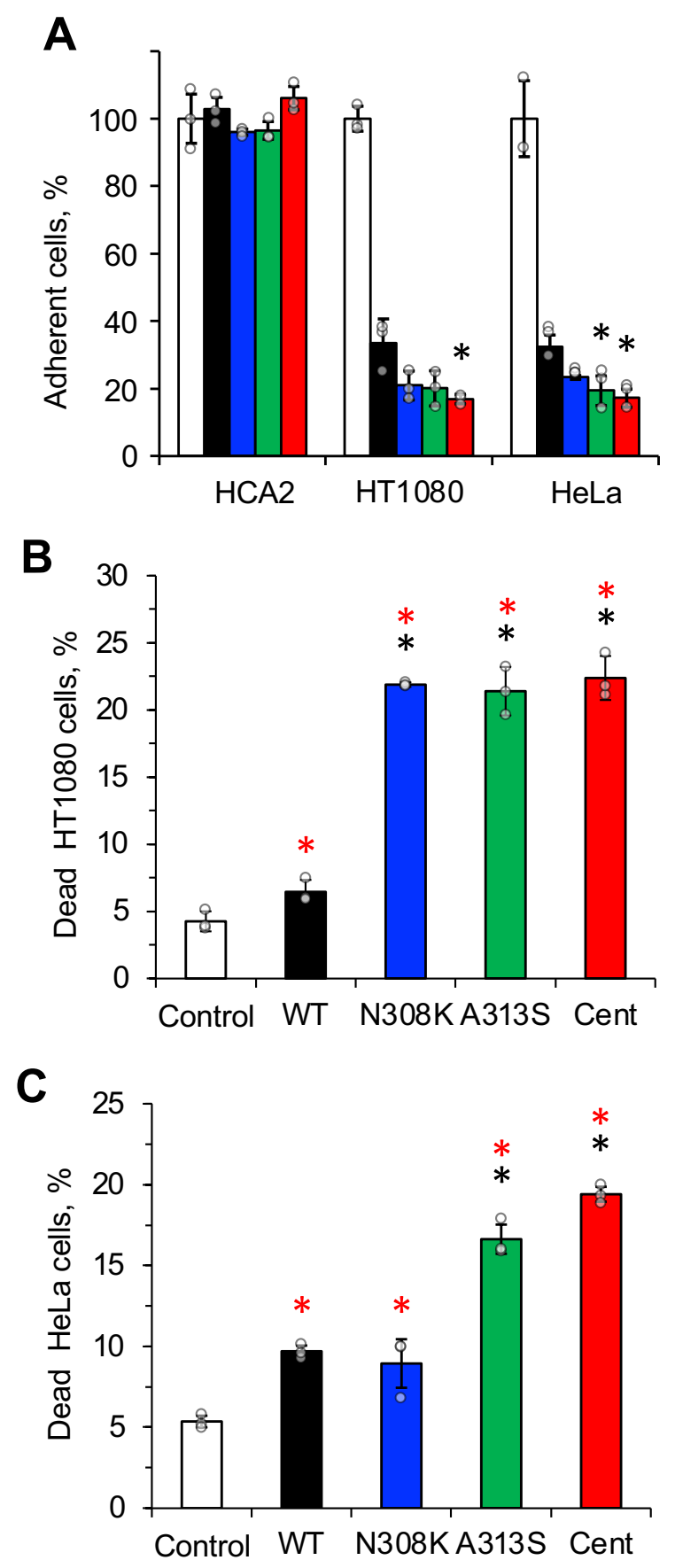

$\square$ Control; $\square$ SIRT6 wt; $\square$ SIRT6 N308K; $\square$ SIRT6 A313S; $\square$ CentSIRT6 
A

\begin{tabular}{|l|l|c|c|}
\hline \multicolumn{1}{|c|}{ Name } & \multicolumn{1}{|c|}{ Description } & Peptides & $\boldsymbol{p}$ value \\
\hline RBP56 & TATA-binding protein-associated factor 2N & 5 & 0.0002 \\
\hline LMNA & Prelamin-A/C & $\mathbf{3 8}$ & $\mathbf{0 . 0 0 2 5}$ \\
\hline RL35 & 60S ribosomal protein L35 & 4 & 0.0056 \\
\hline CEBPB & CCAAT/enhancer-binding protein beta & 1 & 0.0119 \\
\hline VIME & Vimentin & 40 & 0.0188 \\
\hline NUMA1 & Nuclear mitotic apparatus protein 1 & 2 & 0.0227 \\
\hline NOL6 & Nucleolar protein 6 & 2 & 0.0250 \\
\hline FRG1 & Protein FRG1 & 2 & 0.0336 \\
\hline A0A0B4J2E5 & Uncharacterized protein & 3 & 0.0354 \\
\hline PHRF1 & PHD and RING finger domain-containing protein 1 & 3 & 0.0445 \\
\hline H15 & Histone H1.5 & 11 & 0.0516 \\
\hline H31 & Histone H3.1 & 3 & 0.0534 \\
\hline NOL10 & Nucleolar protein 10 & 1 & 0.0581 \\
\hline
\end{tabular}

C SIRT6 associated LMNA

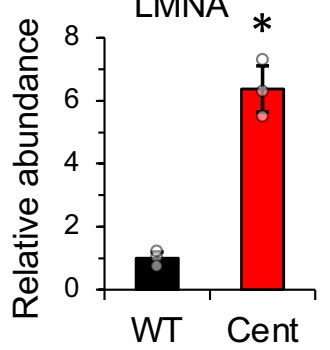

D LMNA associated SIRT6

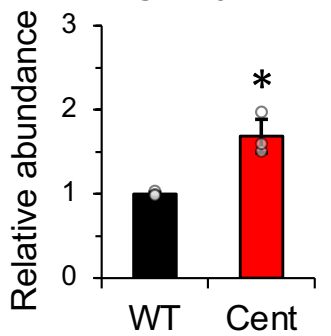

B

E Ribosylated SIRT6

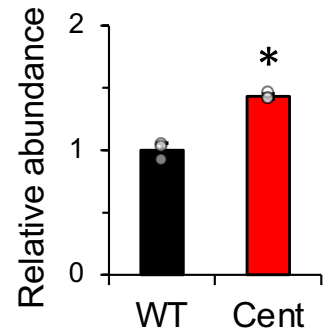

WT Cent

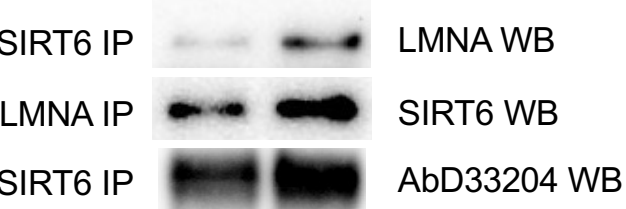

AbD33205 IP $\longrightarrow$ LMNA WB

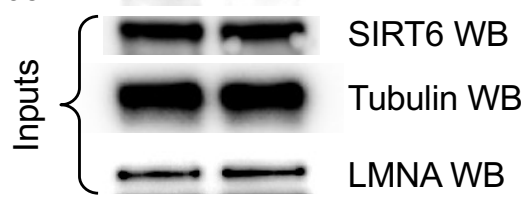

$\mathbf{G}$

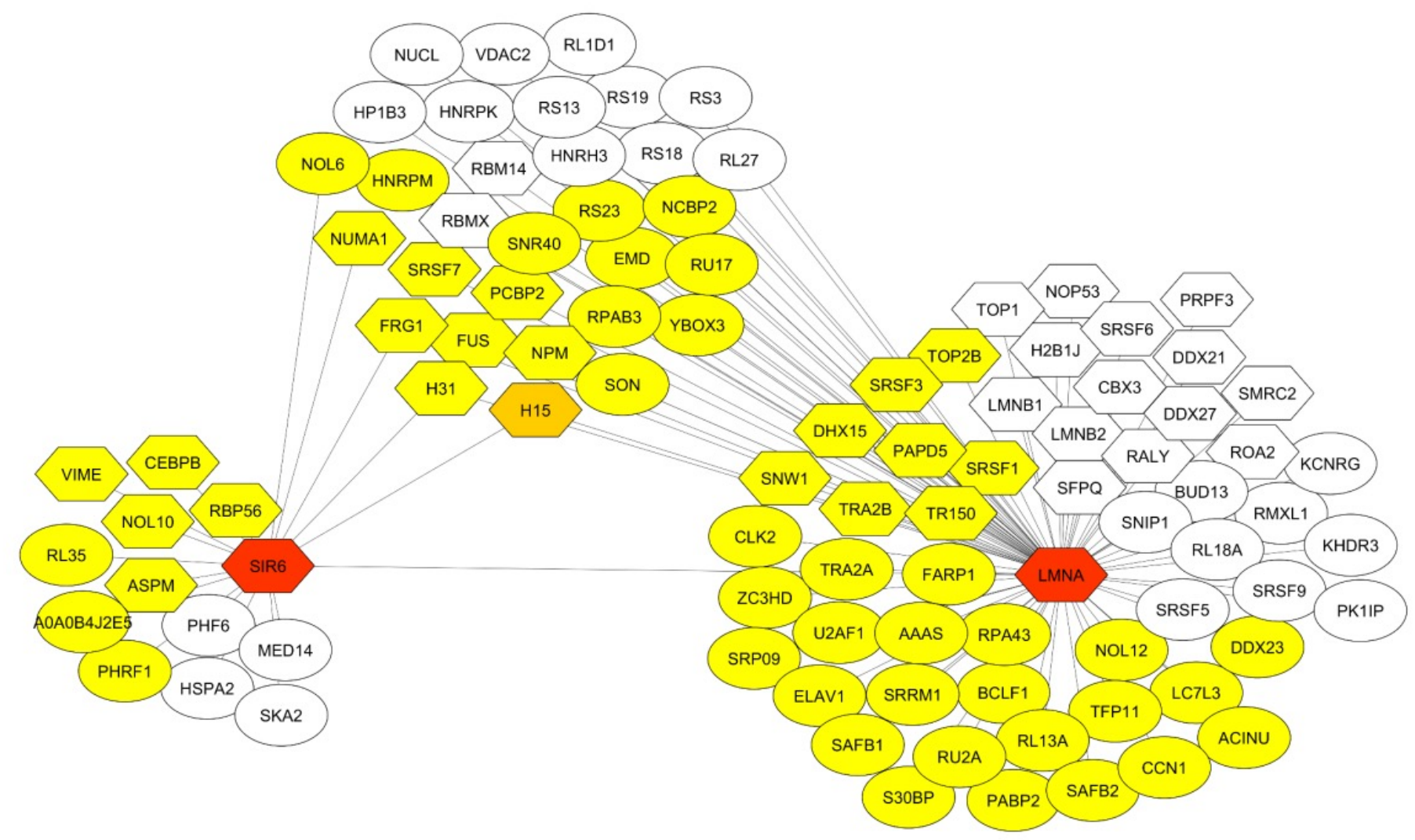


bioRxiv preprint doi: https://doi.org/10.1101/2021.12.13.472381; this version posted December 13, 2021. The copyright holder for this preprint (which was not certified by peer review) is the author/funder, who has granted bioRxiv a license to display the preprint in perpetuity. It is made available under aCC-BY-NC-ND 4.0 International license.

FIG 7

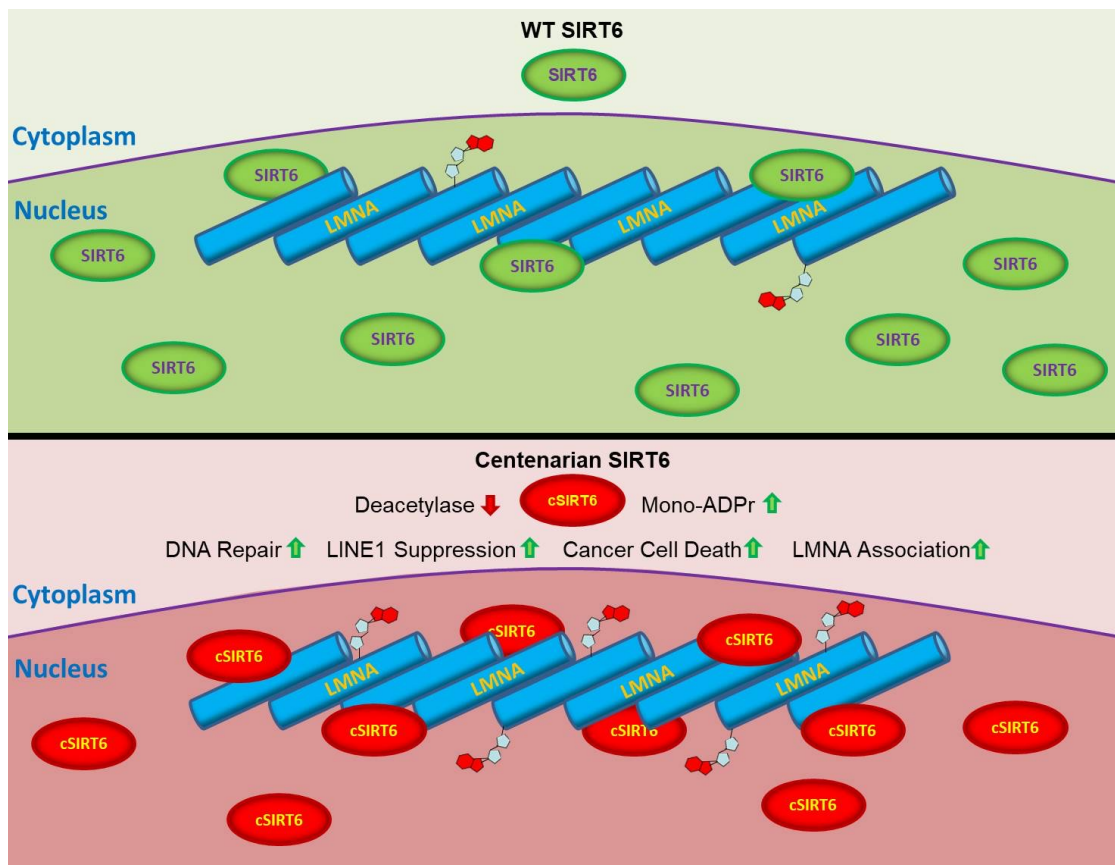


bioRxiv preprint doi: https://doi.org/10.1101/2021.12.13.472381; this version posted December 13, 2021. The copyright holder for this preprint (which was not certified by peer review) is the author/funder, who has granted bioRxiv a license to display the preprint in perpetuity. It is made available under aCC-BY-NC-ND 4.0 International license.

A

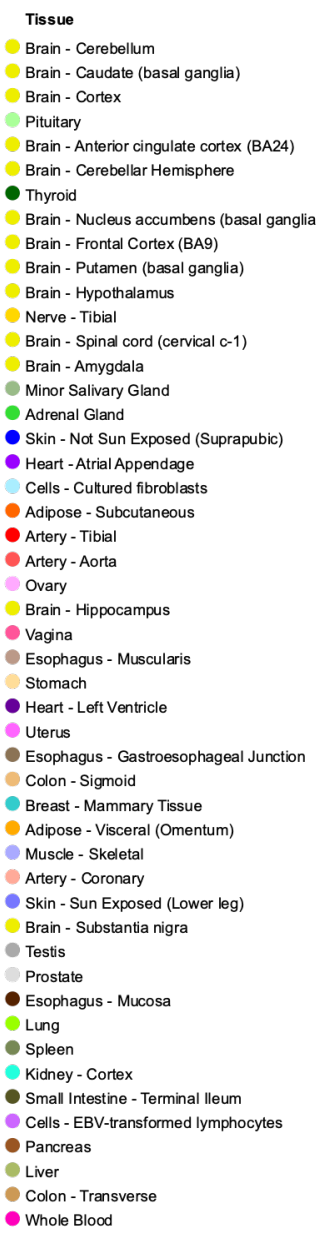

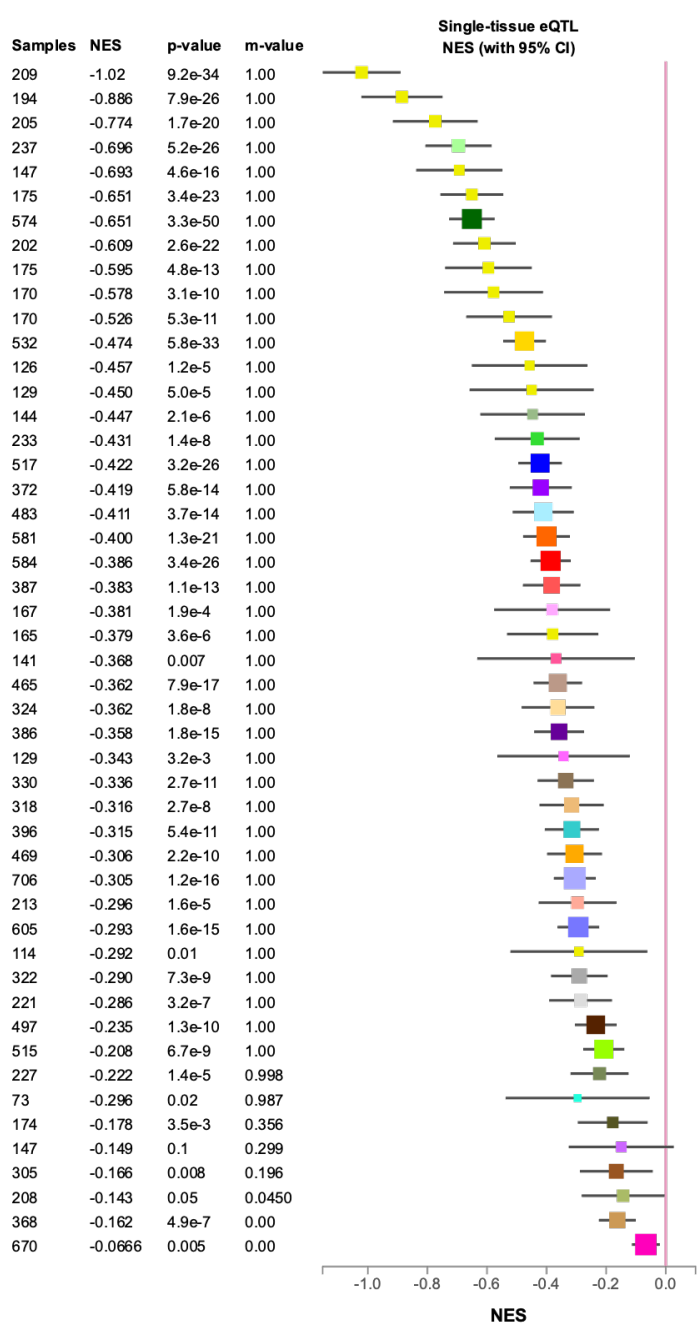

B

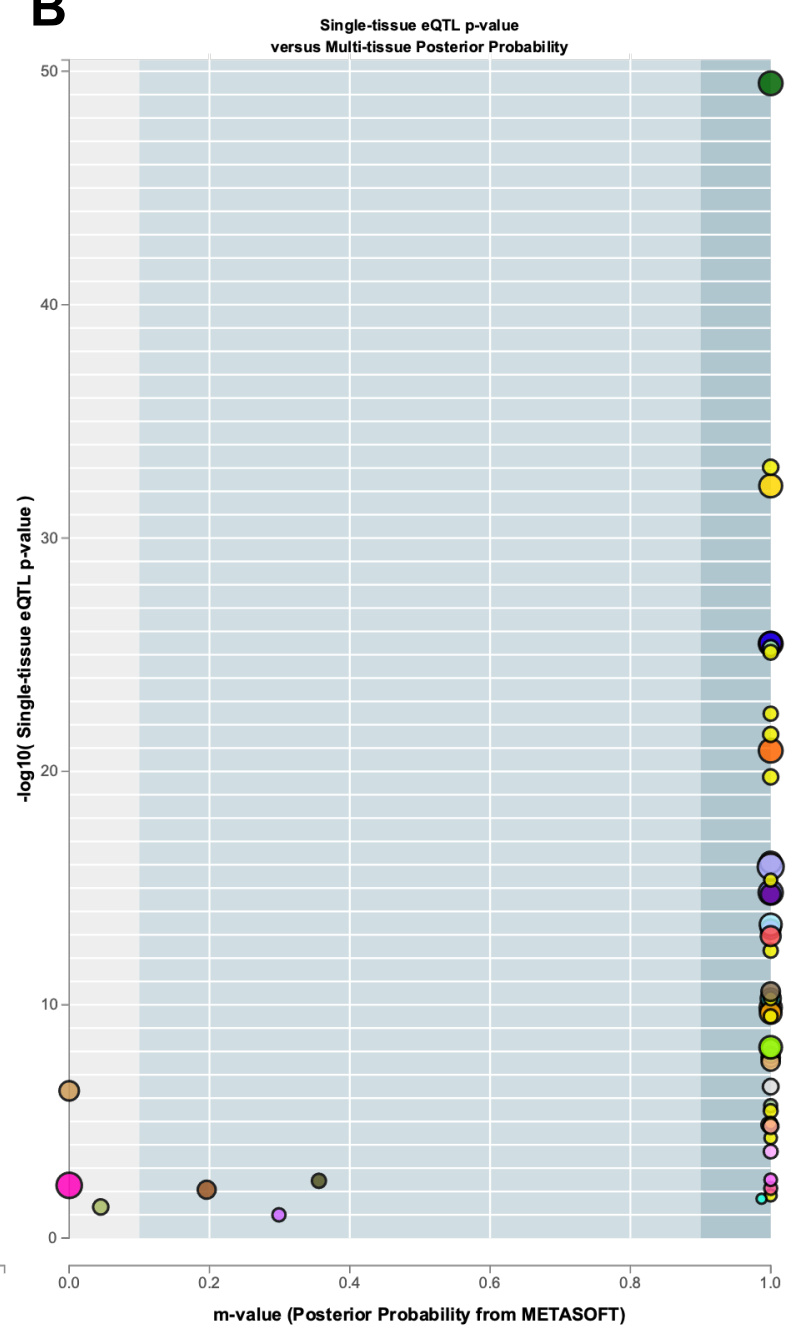

C
SIRT6

chr19_4174953_A_G_b38

Brain - Cerebellum

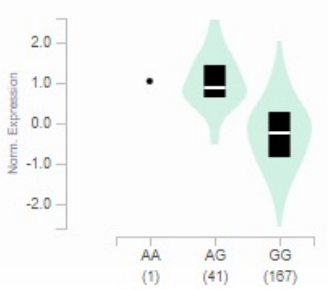

SIRT6

chr19_4174953_A_G_b38

Heart - Atrial Appendage

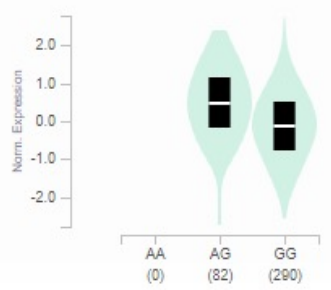

FIG EV1 (n)

\section{,}



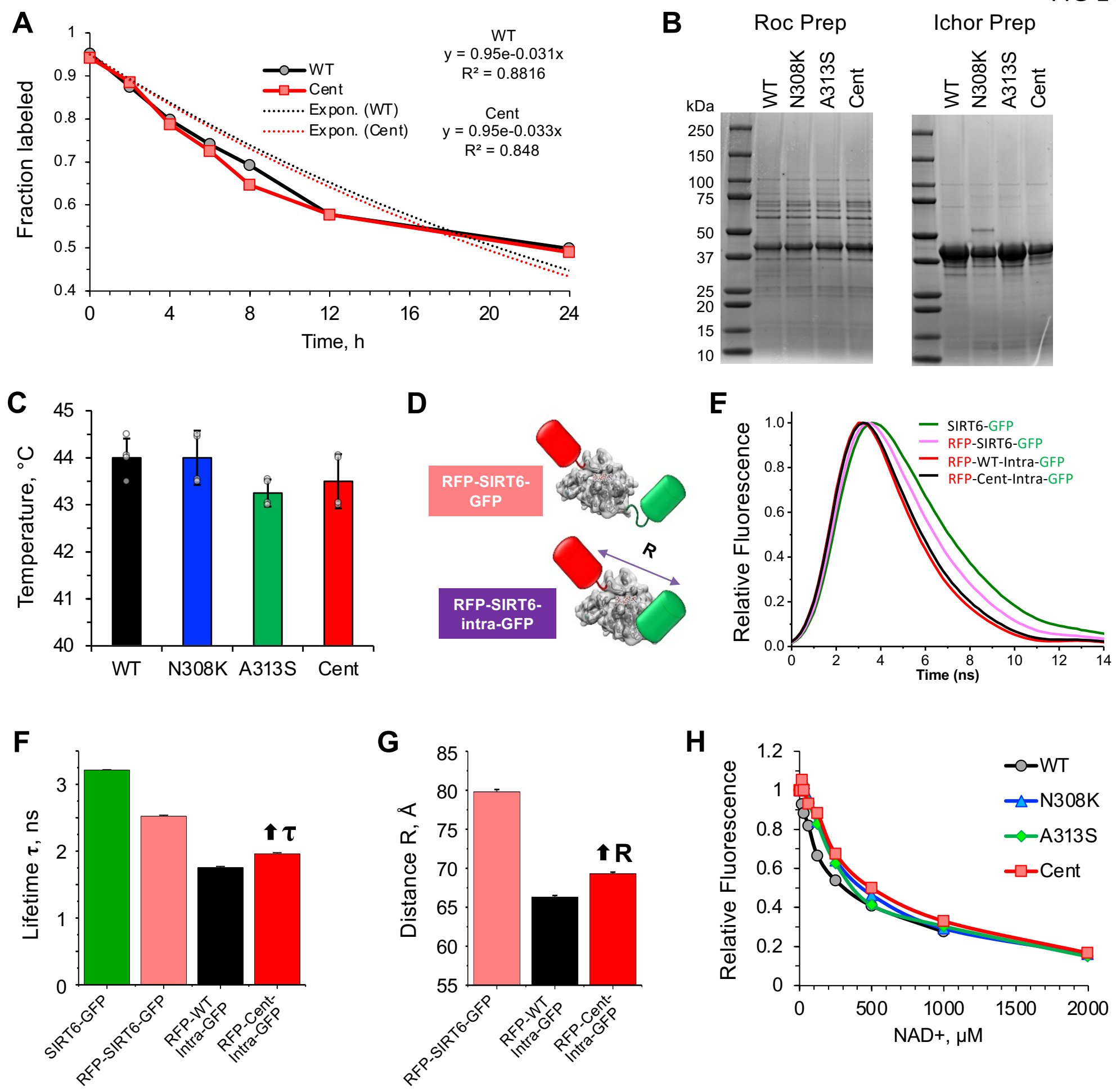
A
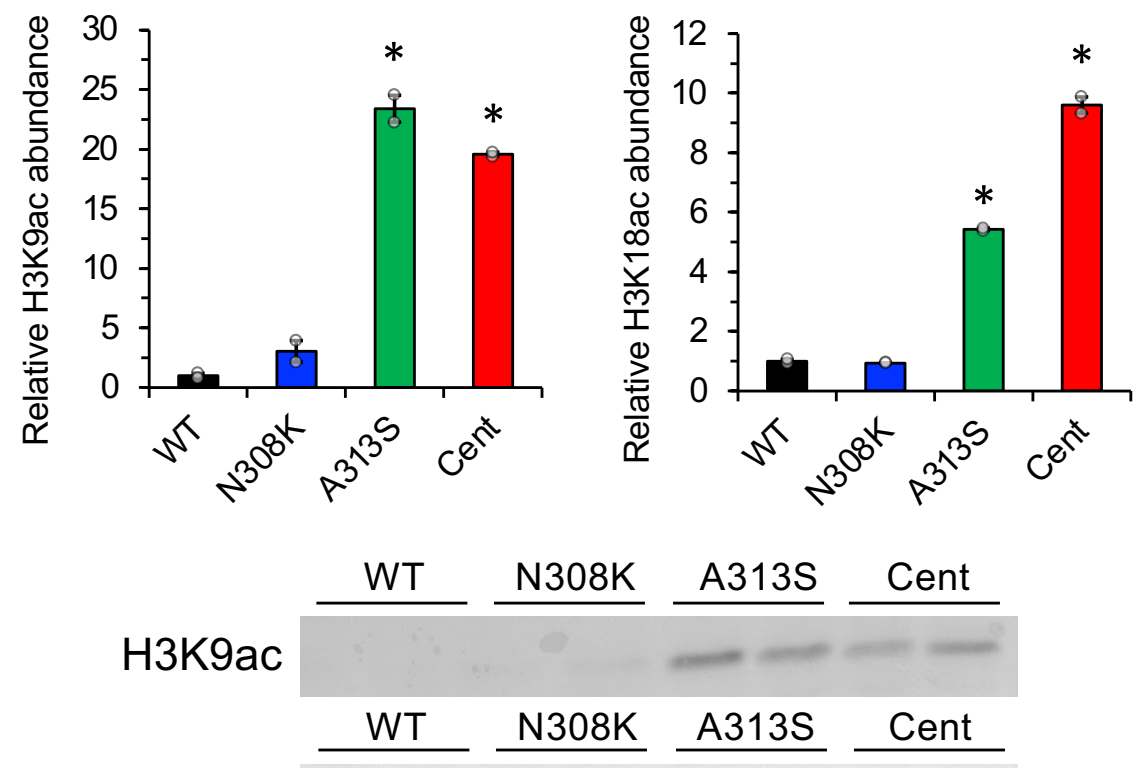

H3K18ac

B

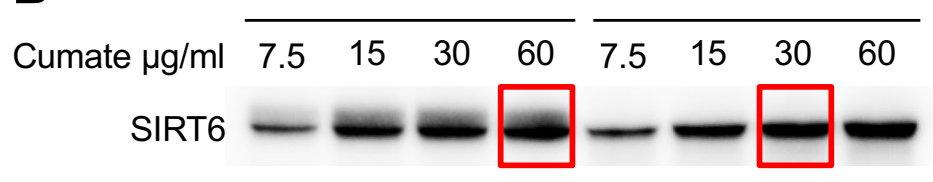

C

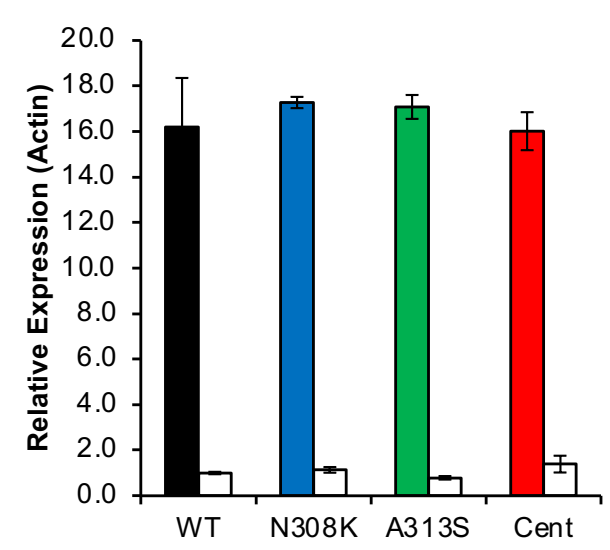


FIG EV4

A
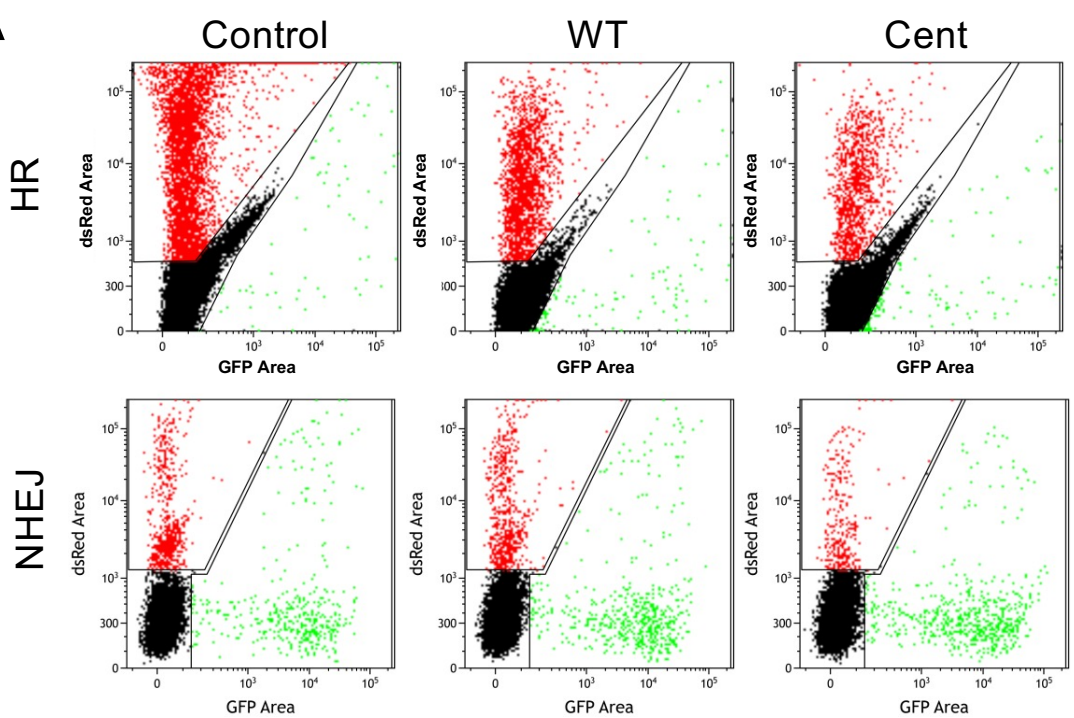

B
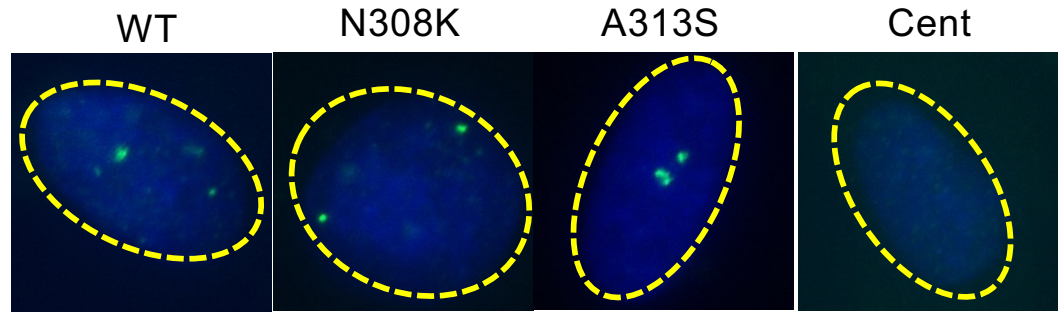

C

$0.5 \mathrm{hr}$
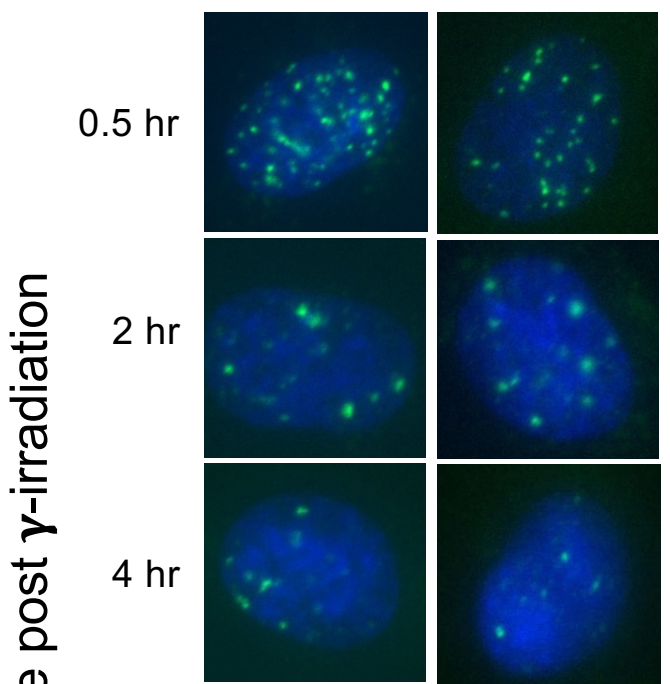

$24 \mathrm{hr}$
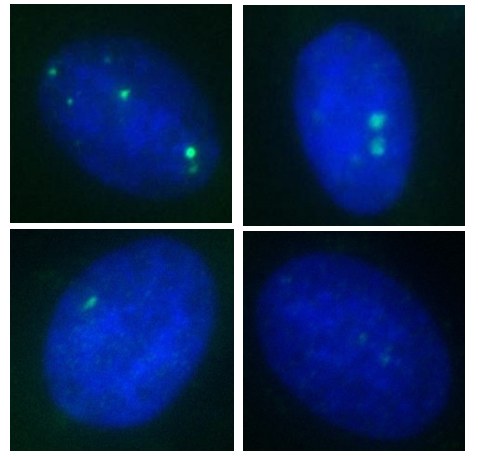

D

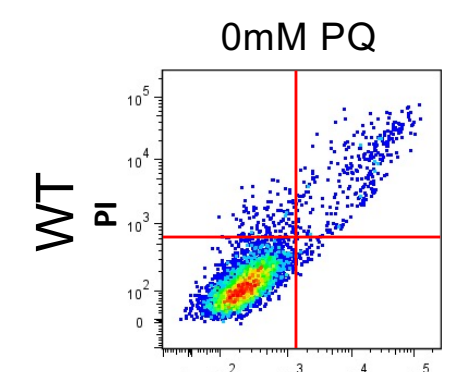

Basal

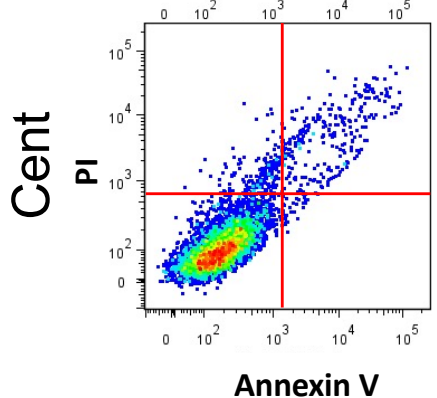

Annexin V
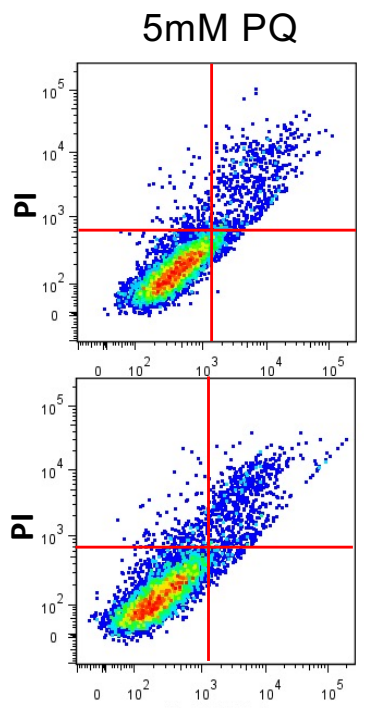

Annexin V

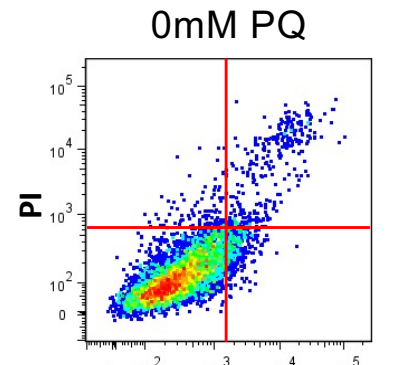

Induced

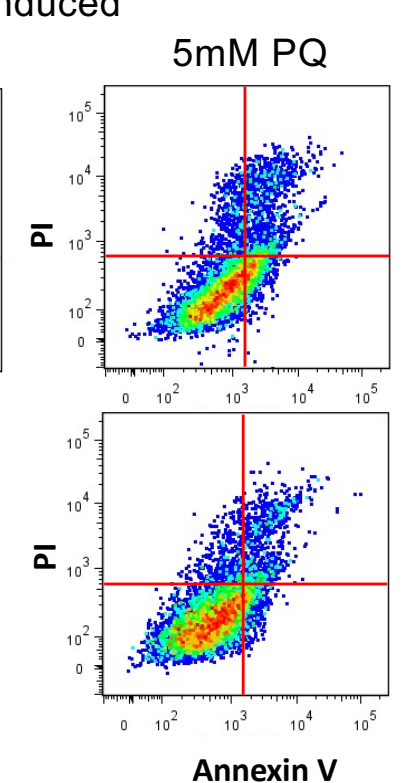


A

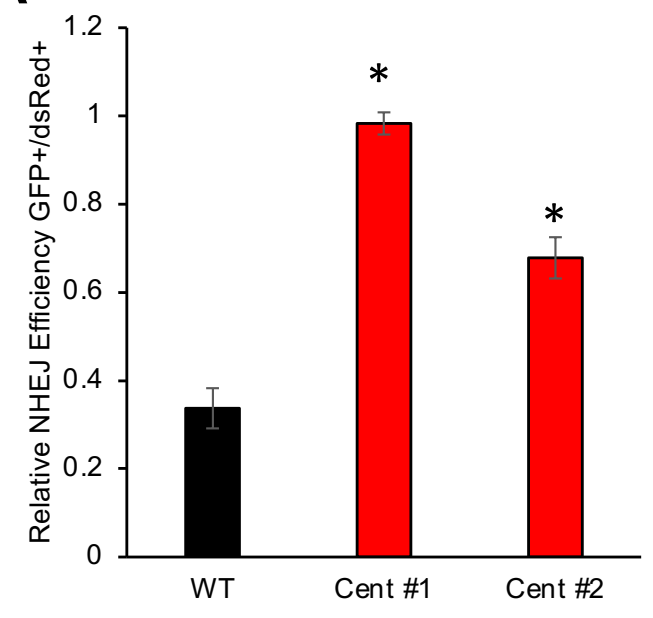

C

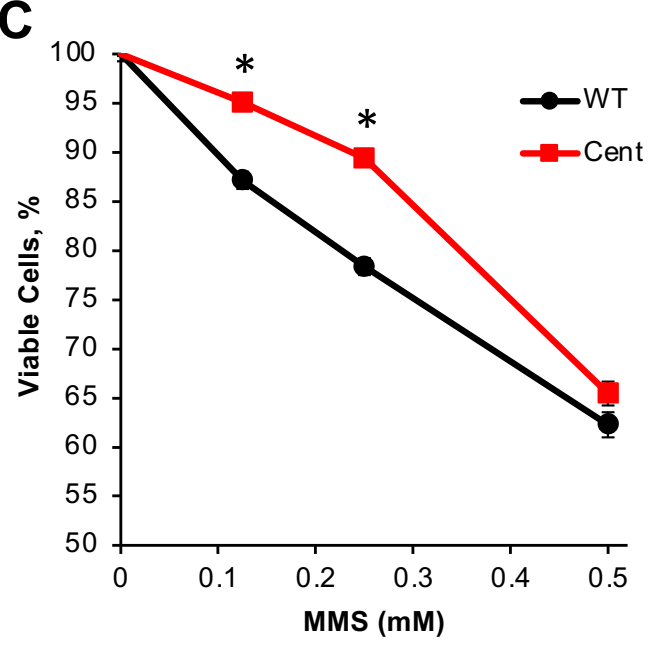

B

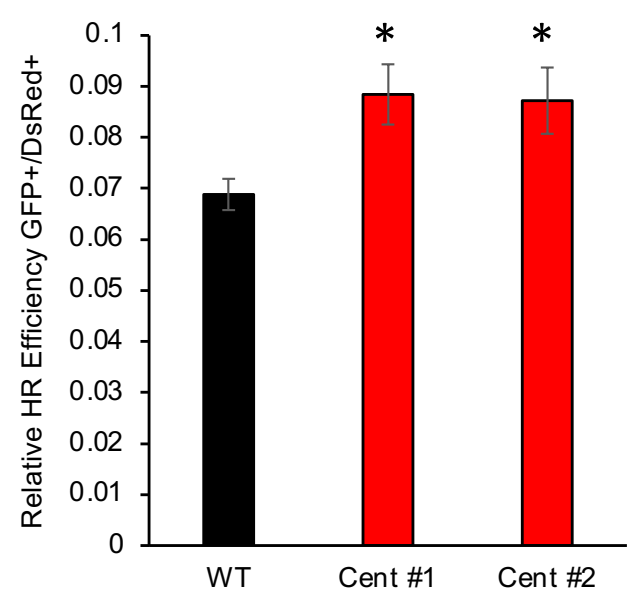

FIG EV5

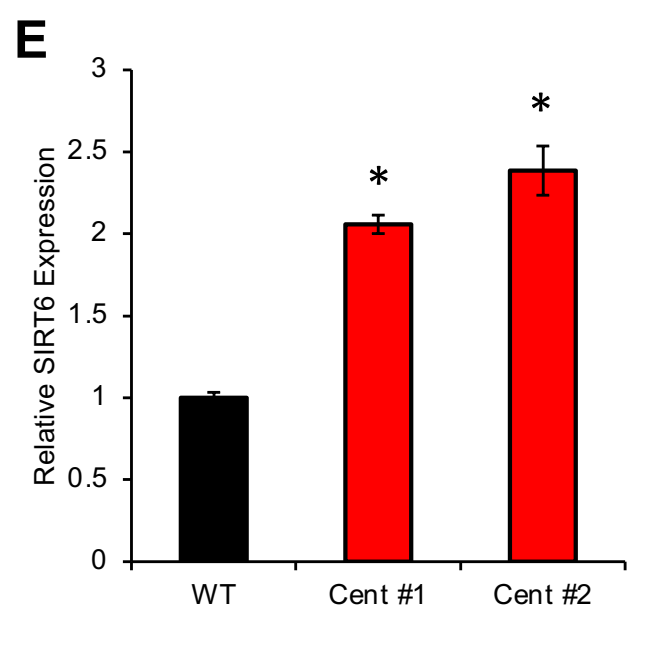

F

D

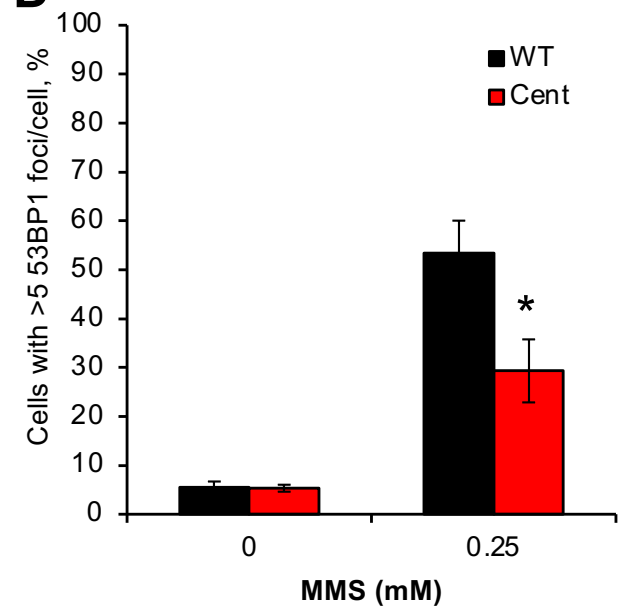

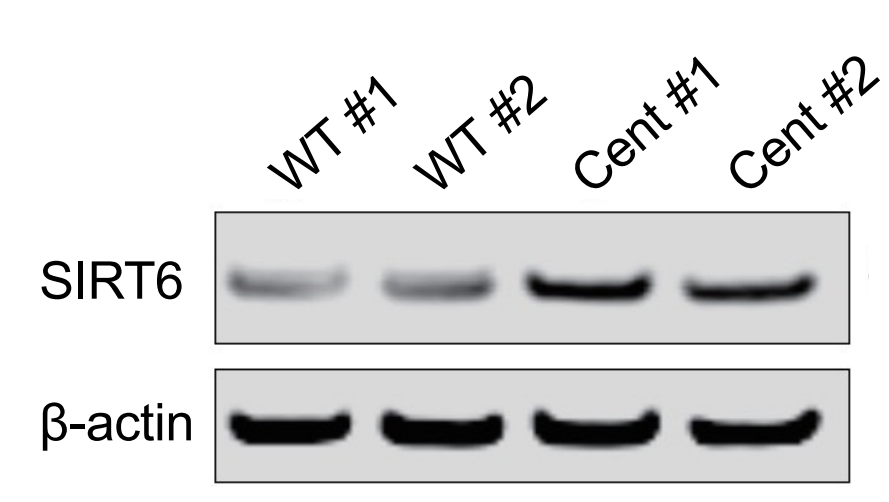

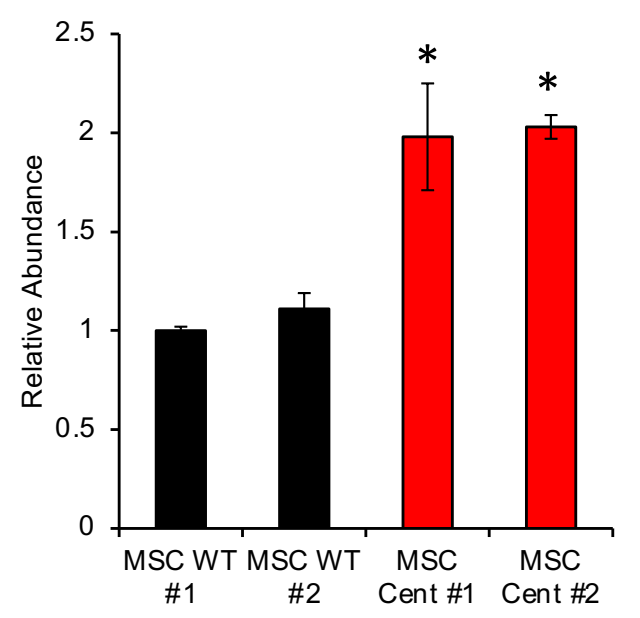

